Research Article

\title{
Comparison of Mechanical Properties of Cement-Stabilized Loess Produced Using Different Compaction Methods
}

\author{
Yingjun Jiang (iD, Kejia Yuan (iD, Qilong Li, Changqing Deng, Yong Yi, Yu Zhang, \\ and Jinshun Xue
}

Key Laboratory for Special Area Highway Engineering of Ministry of Education, Chang'an University, South 2nd Ring Rd., Middle Section, Xi'an, Shaanxi 710064, China

Correspondence should be addressed to Kejia Yuan; 2019021081@chd.edu.cn

Received 27 July 2020; Revised 21 August 2020; Accepted 24 August 2020; Published 7 October 2020

Academic Editor: Hossein Moayedi

Copyright ( 92020 Yingjun Jiang et al. This is an open access article distributed under the Creative Commons Attribution License, which permits unrestricted use, distribution, and reproduction in any medium, provided the original work is properly cited.

Mechanical properties are important indexes to evaluate the improvement effect and engineering performance of cementstabilized loess (CSL). This paper presents a comparison of the mechanical properties of CSL compacted using hammer quasistatic compaction method (QSCM) and vertical vibration compaction method (VVCM). The compaction properties, unconfined compressive strength (UCS), splitting strength (SPS), and resilient modulus (RM) of the laboratory-compacted CSL using VVCM and QSCM are tested and compared. Furthermore, the effects of compaction method, cement content, compaction coefficient, and curing time of the CSL specimens are investigated. In addition, field measurements are carried out to validate the laboratory investigations. The results show that the laboratory-compacted CSL using VVCM has a larger dry density and smaller optimum water content than that using QSCM. And the compaction method has a great influence on the mechanical strength of CSL. The UCS, SPS, and RM of the specimen produced using VVCM are averagely 1.17 times, 1.49 times, and 1.17 times that of CSL produced using QSCM, respectively, and the UCS, SPS, and RM of the specimens produced using these two methods increase linearly as the cement content and compaction coefficient increase, while the mechanical strength growth curve experiences three periods of increasing sharply, increasing slowly, and stabilizing with the curing time increased. Moreover, the results also show that the mechanical properties of laboratory-compacted CSL using VVCM have a better correlation of $83.8 \%$ with the field core samples.

\section{Introduction}

In recent years, the construction of intercity railway has promoted the economic development and optimized the transportation capacity. With the increasing construction of intercity railway, more stringent requirements are put forward for the subgrade engineering. The subgrade of intercity railway is generally composed of three parts: subgrade bed, filling below the bottom layer of subgrade bed, and foundation soil. As the weakest part of subgrade structure under the dynamic traffic load, the filling at the bottom of subgrade bed is inclined to be compacted and deformed, not only affecting the planeness of the track structure, reducing the safety and speed of train, but also raising the difficulty of railway maintenance. When the subgrade is in adverse climate and hydrological conditions for a long time, the structure of soil and the properties of filler are changed, thus resulting in the reduction of bearing capacity and stability of the subgrade. Therefore, the high strength, high stiffness, and high stability of subgrade are the precondition to ensure the safety, high speed, and stability of the train.

The engineering properties of subgrade are closely related to the properties of filling materials. When the intercity railway is constructed in the Guanzhong Basin of Shaanxi Province, it is inevitable to pass through widely distributed loess. Loess, as a kind of Quaternary Aeolian sedimentary silt, is mainly composed of silt and has large pores with particle size about $1 \mathrm{~mm}$, which leads to developed vertical joints, metastable structure, and collapsibility in varying degrees $[1,2]$. Moreover, it has low bearing capacity and high compressibility and is prone to significant subsidence after 
TABLE 1: Technical properties of loess.

\begin{tabular}{|c|c|c|c|c|c|c|c|c|c|}
\hline \multirow{3}{*}{$\begin{array}{l}\text { Collapsibility grade of } \\
\text { loess }\end{array}$} & \multicolumn{9}{|c|}{ Technical index } \\
\hline & \multirow{2}{*}{$\begin{array}{l}\text { Density } \\
\left(\mathrm{g} / \mathrm{cm}^{3}\right)\end{array}$} & \multirow{2}{*}{$\begin{array}{l}\text { Liquid limit } \\
\qquad \%)\end{array}$} & \multirow{2}{*}{$\begin{array}{l}\text { Plastic limit } \\
\quad(\%)\end{array}$} & \multirow{2}{*}{$\begin{array}{l}\text { Plasticity } \\
\text { index }\end{array}$} & \multicolumn{5}{|c|}{$\begin{array}{l}\text { Passing ratio (by mass) } \begin{array}{l}(\%) \text { as a function of sieve size } \\
(\mathrm{mm})\end{array}\end{array}$} \\
\hline & & & & & $0.25-0.075$ & $0.075-0.05$ & $0.05-0.01$ & $0.01-0.005$ & $\leq 0.005$ \\
\hline IV & 2.74 & 26.4 & 15.7 & 10.7 & 2.47 & 7.22 & 53.43 & 13.83 & 23.05 \\
\hline
\end{tabular}

TABLE 2: Technical properties of cement.

\begin{tabular}{|c|c|c|c|c|c|c|}
\hline \multirow[t]{2}{*}{ Fineness (\%) } & \multirow[t]{2}{*}{ Soundness (mm) } & \multirow[t]{2}{*}{ Loss on ignition (\%) } & \multicolumn{2}{|c|}{ Setting time (min) } & \multicolumn{2}{|c|}{$\begin{array}{l}\text { Three-dimensional strength } \\
(\mathrm{MPa})(28 \mathrm{~d})\end{array}$} \\
\hline & & & Initial time & Final time & Flexural & Compressive \\
\hline 1.2 & 2.05 & 1.02 & 265 & 320 & 8.06 & 38.99 \\
\hline
\end{tabular}

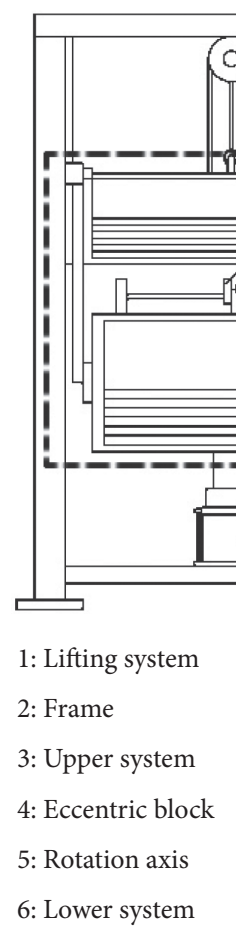

6: Lower system

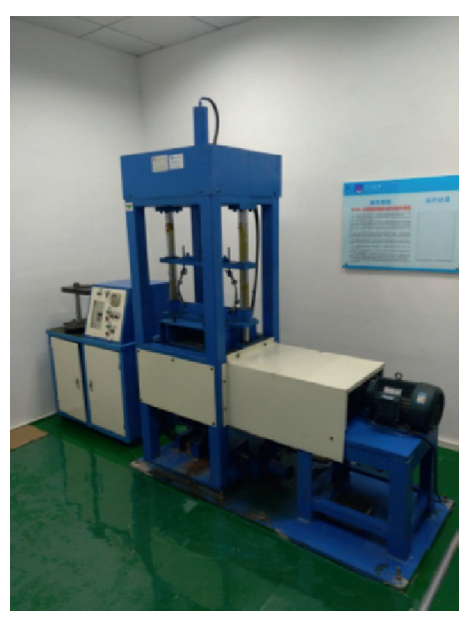

7: Vibratory hammer

8: Test mold

9: Control system

10: Rotation axis

11: Electric motor

12: Vibration system

(a) (b)

Figure 1: (a) Diagram of VVTE; (b) photograph of VVTE in laboratory.

TABLE 3: Working parameters of vertical vibration testing equipment.

\begin{tabular}{|c|c|c|c|c|}
\hline \multirow{2}{*}{ Frequency $(\mathrm{Hz})$} & \multirow{2}{*}{ Nominal amplitude (mm) } & \multicolumn{3}{|c|}{ Mass (kg) } \\
\hline & & Upper system & Lower system & Working weight \\
\hline $35 \pm 1$ & $1.3 \pm 0.05$ & $120 \pm 1$ & $180 \pm 1$ & $300 \pm 2$ \\
\hline
\end{tabular}

immersion. The Chinese national standards "Code for Design of Intercity Railway" (TB10623-2014) and "Code for Design of Railway Earth Structure" (TB10001-2016) stipulate that filling materials including Groups A and B should be used for filling the subgrade bed and below, but loess is classified as Group C filler $[3,4]$. When applied to railway subgrade engineering, it usually brings about engineering geological problems such as subgrade subsidence and serious decrease of strength and stiffness [5-7]. However, due to its low price and wide distribution in China, it is often used after physical or chemical stabilization to improve the strength, stiffness, and stability of loess subgrade. 
TABLE 4: The standard technical parameters of heavy compaction test (HCT-Z1).

\begin{tabular}{|c|c|c|c|c|c|c|c|c|c|}
\hline \multicolumn{6}{|c|}{ Compaction device specifications } & \multicolumn{4}{|c|}{ Testing conditions } \\
\hline \multirow[b]{2}{*}{$\begin{array}{l}\text { Mass } \\
(\mathrm{kg})\end{array}$} & \multicolumn{2}{|c|}{ Hammer } & \multicolumn{3}{|c|}{ Compaction mold } & \multirow[b]{2}{*}{$\begin{array}{c}\text { Compaction } \\
\text { work } \\
\left(\mathrm{kJ} / \mathrm{m}^{3}\right)\end{array}$} & \multirow[b]{2}{*}{$\begin{array}{l}\text { Number of } \\
\text { layers }\end{array}$} & \multirow[b]{2}{*}{$\begin{array}{c}\text { Striking } \\
\text { times }\end{array}$} & \multirow[b]{2}{*}{$\begin{array}{l}\text { Maximum } \\
\text { particle size } \\
\quad(\mathrm{mm})\end{array}$} \\
\hline & $\begin{array}{c}\text { Bottom } \\
\text { diameter } \\
(\mathrm{mm})\end{array}$ & $\begin{array}{c}\text { Drop } \\
\text { distance } \\
(\mathrm{mm})\end{array}$ & $\begin{array}{c}\text { Inner } \\
\text { diameter } \\
(\mathrm{mm})\end{array}$ & $\begin{array}{c}\text { Height } \\
(\mathrm{mm})\end{array}$ & $\begin{array}{c}\text { Volume } \\
(\mathrm{mm})\end{array}$ & & & & \\
\hline 4.5 & 51 & 457 & 102 & 116 & 947.4 & 2659 & 5 & 25 & 5 \\
\hline
\end{tabular}

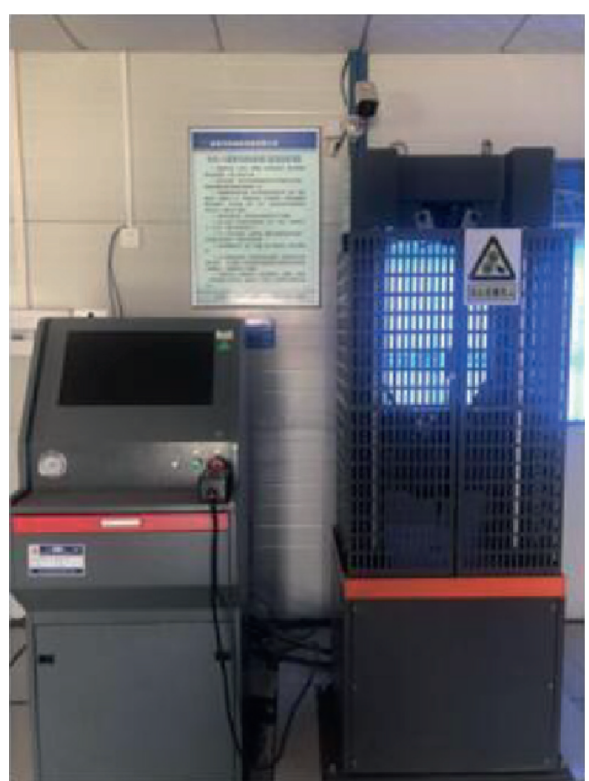

FIgURE 2: Photograph of WAW-100 in laboratory.

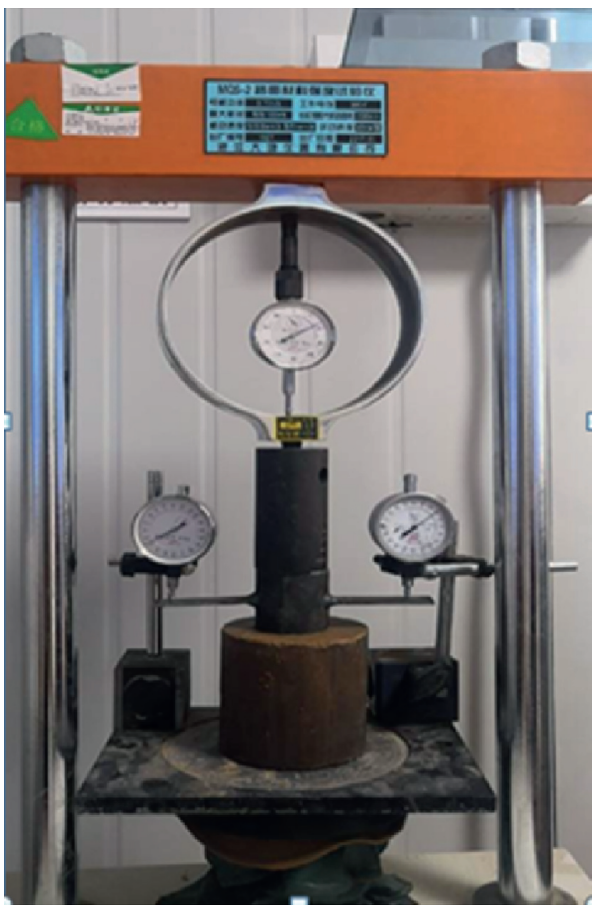

FIgUre 3: Photograph of resilient modulus test for CSL.
The principle of physical stabilization of loess is increasing the compaction coefficient of the soil. Common physical stabilization methods include strong compaction method, compact pile method, and impact compaction method. The chemical stabilization method changes the chemical composition of filler by adding solidified material into the loess. Through the hydration reaction, ion exchange, and gelation of these materials, the loess can be cemented into holistic materials, so as to improve their engineering performance. The chemical stabilization materials, such as cement $[8,9]$, fly ash $[9,10]$, lime $[5,11]$, modified phosphogypsum [12], and fiber [13], have been applied in loess subgrade. In particular, cement is most commonly used. Therefore, extensive attentions have been paid to investigate the improvement effect [14], physical mechanics $[15,16]$, deformation properties [17], dynamic stability [18], and microstructure $[19,20]$ of the cement-stabilized loess (CSL), which are considered as the primary properties of CSL.

In terms of reinforcement mechanism, Liu et al. [8] found that cement can improve microstructure of loess, increase clay content, and enhance cementation, thus increasing the strength; Zhang et al. [10] found that using cement can effectively cut off the infiltration path of cement specimens; Zhao et al. [12] used cement to reinforce the subgrade loess and found that the hydration reaction product can fill the pores and restrict the movement of the soil particles, then the strength of the modified loess is increased, and physical properties are improved; Croft [21] investigated the solidification mechanism of cement modified soil and pointed out that the cementation effect of cement improvement and lime improvement was similar, and the hydrate can effectively increase the strength of improved soil; Mohamed [22] combined scanning electron microscope and X-ray diffraction to determine the ions affecting the structure and strength of cement-stabilized soil: $\mathrm{Al}^{3+}, \mathrm{Ca}^{2+}$, and $\mathrm{Mg}^{2+}$; Zhang et al. [20] investigated the structure and collapsibility through using scanning electron microscopy and indicated that the collapsibility of loess is closely related to its structure; the cement can regroup and bind the loess particles, so that collapsibility can be eliminated to some extent. On the influence of cement content, Zhang et al. [14] explored the stabilization of geotechnical characteristics of loess and revealed that cement proportions had an effective role in the enhancement of compressibility; $\mathrm{Su}$ [15] analyzed the relationship between unconfined compression strength of improved soil and the content of cement and indicated that when the cement mixture ratio was between $4 \%$ and $14 \%$, the scope of increases was quite obvious; Uddin et al. [23], Lee et al. [24], and Ghadakpour 
TABLE 5: Maximum dry density and optimum water content of the CSL.

\begin{tabular}{|c|c|c|c|c|c|c|}
\hline \multirow[b]{2}{*}{ Cement content (\%) } & \multicolumn{2}{|c|}{ QSCM } & \multicolumn{2}{|c|}{ VVCM } & \multirow[b]{2}{*}{$\rho_{\max , 2} / \rho_{\max , 1}$} & \multirow[b]{2}{*}{$w_{\mathrm{opt}, 2} / w_{\mathrm{opt}, 1}$} \\
\hline & $\rho_{\max , 1}\left(\mathrm{~g} / \mathrm{cm}^{3}\right)$ & $w_{\mathrm{opt}, 1}(\%)$ & $\rho_{\max , 2}\left(\mathrm{~g} / \mathrm{cm}^{3}\right)$ & $w_{\mathrm{opt}, 2}(\%)$ & & \\
\hline 3 & 1.993 & 11.3 & 2.018 & 10.6 & 1.013 & 0.94 \\
\hline 4 & 1.998 & 11.4 & 2.030 & 10.9 & 1.016 & 0.96 \\
\hline 5 & 2.004 & 11.5 & 2.032 & 11.0 & 1.014 & 0.96 \\
\hline 6 & 2.010 & 11.6 & 2.034 & 11.2 & 1.012 & 0.97 \\
\hline
\end{tabular}

TABLE 6: Unconfined compressive strength of CSL compacted using VVCM and QSCM.

\begin{tabular}{|c|c|c|c|c|c|c|}
\hline \multirow{2}{*}{ Compaction method } & \multirow{2}{*}{ Curing time (day) } & \multirow{2}{*}{ Cement content $(\%)$} & \multicolumn{4}{|c|}{ UCS at different compaction coefficient (MPa) } \\
\hline & & & 0.92 & 0.95 & 0.97 & 1.00 \\
\hline \multirow{20}{*}{ QSCM } & \multirow{4}{*}{7} & 3 & 0.97 & 1.10 & 1.36 & 1.63 \\
\hline & & 4 & 1.11 & 1.38 & 1.66 & 1.96 \\
\hline & & 5 & 1.28 & 1.59 & 1.89 & 2.18 \\
\hline & & 6 & 1.51 & 1.78 & 2.10 & 2.42 \\
\hline & \multirow{4}{*}{14} & 3 & 1.19 & 1.33 & 1.78 & 2.03 \\
\hline & & 4 & 1.32 & 1.66 & 2.08 & 2.44 \\
\hline & & 5 & 1.56 & 1.85 & 2.27 & 2.63 \\
\hline & & 6 & 1.86 & 2.16 & 2.49 & 2.91 \\
\hline & \multirow{4}{*}{28} & 3 & 1.30 & 1.60 & 2.03 & 2.39 \\
\hline & & 4 & 1.49 & 1.90 & 2.26 & 2.65 \\
\hline & & 5 & 1.82 & 2.21 & 2.63 & 3.06 \\
\hline & & 6 & 2.03 & 2.44 & 2.80 & 3.24 \\
\hline & \multirow{4}{*}{60} & 3 & 1.41 & 1.74 & 2.20 & 2.61 \\
\hline & & 4 & 1.63 & 2.06 & 2.46 & 2.87 \\
\hline & & 5 & 1.95 & 2.37 & 2.76 & 3.19 \\
\hline & & 6 & 2.23 & 2.65 & 3.08 & 3.52 \\
\hline & \multirow{4}{*}{90} & 3 & 1.52 & 1.89 & 2.31 & 2.72 \\
\hline & & 4 & 1.75 & 2.19 & 2.58 & 3.03 \\
\hline & & 5 & 2.06 & 2.54 & 2.87 & 3.34 \\
\hline & & 6 & 2.36 & 2.81 & 3.21 & 3.64 \\
\hline \multirow{20}{*}{ VVCM } & \multirow{5}{*}{7} & 3 & 1.03 & 1.22 & 1.52 & 1.89 \\
\hline & & 4 & 1.21 & 1.58 & 1.95 & 2.32 \\
\hline & & 5 & 1.43 & 1.80 & 2.17 & 2.59 \\
\hline & & 6 & 1.72 & 1.96 & 2.61 & 2.92 \\
\hline & & 3 & 1.29 & 1.56 & 2.08 & 2.61 \\
\hline & \multirow{3}{*}{14} & 4 & 1.46 & 1.88 & 2.45 & 3.00 \\
\hline & & 5 & 1.73 & 2.12 & 2.84 & 3.26 \\
\hline & & 6 & 1.94 & 2.35 & 3.10 & 3.65 \\
\hline & \multirow{4}{*}{28} & 3 & 1.47 & 1.82 & 2.46 & 2.87 \\
\hline & & 4 & 1.62 & 2.22 & 2.74 & 3.19 \\
\hline & & 5 & 1.95 & 2.49 & 3.02 & 3.63 \\
\hline & & 6 & 2.29 & 2.68 & 3.39 & 4.15 \\
\hline & \multirow{4}{*}{60} & 3 & 1.65 & 2.05 & 2.73 & 3.11 \\
\hline & & 4 & 1.79 & 2.35 & 2.83 & 3.47 \\
\hline & & 5 & 2.20 & 2.89 & 3.39 & 3.99 \\
\hline & & 6 & 2.45 & 3.15 & 3.70 & 4.44 \\
\hline & \multirow{4}{*}{90} & 3 & 1.82 & 2.32 & 2.84 & 3.40 \\
\hline & & 4 & 1.91 & 2.47 & 3.17 & 3.51 \\
\hline & & 5 & 2.39 & 2.95 & 3.53 & 3.91 \\
\hline & & 6 & 2.71 & 3.40 & 3.72 & 4.59 \\
\hline
\end{tabular}

et al. [16] showed that the mechanical strength of cement soil was related to cement content and water content, and there was an optimal cement content; Consoli et al. [25] revealed that the unconfined compressive strength of cement-stabilized soil increased linearly with the increase of cement content. Under the same compaction level, the influence of water content on the compressive strength of cement soil was significantly greater than that of cement content; Wang et al. [18] investigated the cement commingle ratio, water dipping conditions, compacting factor, and vibration frequency on the dynamic characteristics of cement-improved loess and indicated that the dynamic characteristics of cement-improved loess were better with the increase of cement, and there was no optimal ratio of 
TABLE 7: UCS ratio of CSL compacted using VVCM to CSL compacted using QSCM.

\begin{tabular}{|c|c|c|c|c|c|}
\hline \multirow[t]{2}{*}{ Curing time (days) } & \multirow[t]{2}{*}{ Cement content $(\%)$} & \multicolumn{4}{|c|}{$\begin{array}{l}\text { UCS ratio of CSL } \\
\text { compacted using } \\
\text { VVCM to CSL } \\
\text { compacted using } \\
\text { QSCM }\end{array}$} \\
\hline & & 0.92 & 0.95 & 0.97 & 1.00 \\
\hline \multirow{4}{*}{7} & 3 & 1.06 & 1.11 & 1.12 & 1.16 \\
\hline & 4 & 1.10 & 1.14 & 1.17 & 1.18 \\
\hline & 5 & 1.12 & 1.13 & 1.15 & 1.19 \\
\hline & 6 & 1.14 & 1.10 & 1.24 & 1.21 \\
\hline \multirow{4}{*}{14} & 3 & 1.08 & 1.17 & 1.17 & 1.29 \\
\hline & 4 & 1.11 & 1.13 & 1.18 & 1.23 \\
\hline & 5 & 1.11 & 1.15 & 1.25 & 1.24 \\
\hline & 6 & 1.04 & 1.09 & 1.24 & 1.25 \\
\hline \multirow{4}{*}{28} & 3 & 1.13 & 1.14 & 1.21 & 1.20 \\
\hline & 4 & 1.09 & 1.17 & 1.21 & 1.20 \\
\hline & 5 & 1.07 & 1.13 & 1.15 & 1.19 \\
\hline & 6 & 1.13 & 1.10 & 1.21 & 1.28 \\
\hline \multirow{4}{*}{60} & 3 & 1.17 & 1.18 & 1.24 & 1.19 \\
\hline & 4 & 1.10 & 1.14 & 1.15 & 1.21 \\
\hline & 5 & 1.13 & 1.22 & 1.23 & 1.25 \\
\hline & 6 & 1.10 & 1.19 & 1.20 & 1.26 \\
\hline \multirow{4}{*}{90} & 3 & 1.20 & 1.23 & 1.23 & 1.25 \\
\hline & 4 & 1.09 & 1.13 & 1.23 & 1.16 \\
\hline & 5 & 1.16 & 1.16 & 1.23 & 1.17 \\
\hline & 6 & 1.15 & 1.21 & 1.16 & 1.26 \\
\hline
\end{tabular}

cement. With respect to compaction method, Bahar et al. [26] studied the splitting strength, compressive strength, and water stability of cement-stabilized sandy clay by different compaction methods and pointed out that the dynamic compaction method was better than the static compaction method. When the mechanical compaction was combined with chemical stabilization by cement or sand and cement up to a certain level, the cement-stabilized sandy clay would show good compressive strength and better durability at a reasonable cost.

From the aforementioned investigations, it can be perceived that the mechanical properties of CSL are affected by the cement content and compaction method. This can be mainly attributed to the fact that the maximum dry density of CSL is generally affected by the compaction method. Moreover, according to undercompaction theory [27, 28], the mechanical properties of CSL are closely related to the density. When loess is compacted to a considerable density, the primary properties and long-term performance of loess are substantially improved. Therefore, density is a key index affecting the mechanical properties and long-term performance of loess. Since drilling cores from the railway construction for mechanical property testing are uneconomical, the CSL specimens are generally compacted and molded in the laboratory with the same water content and compaction coefficient as in the field. However, the maximum laboratory dry density and compaction coefficient, as the key index for controlling the on-site density and mechanical properties, are mainly due to the laboratory compaction method.
In China, there are two common compaction methods used to evaluate engineering properties and design cement content for loess subgrade engineering, namely, (i) hammer quasi-static compaction method (QSCM) and (ii) vertical vibration compaction method (VVCM). QSCM was based on the performance of compaction equipment in the 1980s. In recent years, the compaction equipment has developed rapidly, the tonnage of vibratory roller has gradually developed from 10-12 $\mathrm{T}$ in the 1980 s to $22-26 \mathrm{~T}$ now, and even $39 \mathrm{~T}$ super tonnage vibratory roller has appeared. The increasing compaction efficiency of vibratory roller leads to the change of compaction mechanism and compaction effect of subgrade, while the standardized testing methods have not been improved accordingly in terms of compaction method, compaction work, and testing process. Therefore, QSCM can rarely simulate the field construction compaction technology, and specimens compacted indoors are difficult to accurately predict the physical and mechanical properties of CSL and effectively guide construction. Studies have indicated that the correlation of mechanical strength between indoor specimens produced using QSCM and field core samples (FCSs) is less than 70\% [29]. However, VVCM is another compaction method which can better simulate the field compaction, and the correlation of mechanical strength between indoor specimens produced using VVCM and field core samples (FCSs) is as high as 90\% [29-31]. Consequently, VVCM has attracted increasing attention in recent years, and it has been applied to macadam stabilized with inorganic binder, asphalt mixture, and graded macadam [32-35], while the application of VVCM in loess has rarely been studied. Therefore, it is of great significance to investigate the mechanical properties of loess compacted using different compaction method. Moreover, validating the laboratory investigations through comparing the results and field measurements is also valuable.

To address this research gap, VVCM and QSCM were used to compact and mold the CSL specimens, and the unconfined compressive strength (UCS), splitting strength (SPS), and resilient modulus (RM) of the CSL specimens were compared. The effect of cement content, curing time, and compaction coefficient on mechanical properties of CSL was also studied. Furthermore, the field core samples (FCSs) in the subgrade were tested to validate the laboratory investigations, which is of great significance to improve the engineering performance of CSL.

\section{Materials and Testing Method}

2.1. Raw Materials. The loess used in the study was taken from the Xi'an-Hancheng intercity railway project, and the cement used was composite Portland cement with a grade of 42.5 and produced by Shaanxi city. The technical properties are presented in Tables 1 and 2.

\subsection{Testing Method}

2.2.1. VVCM. The VVCM was divided into two procedures: (i) the maximum dry density and optimum water content were determined and (ii) CSL specimens were fabricated. 


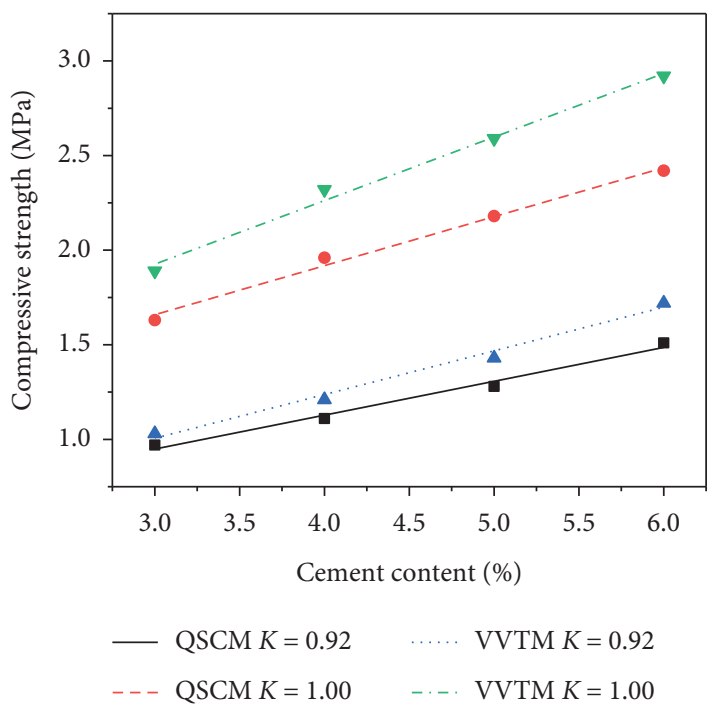

(a)

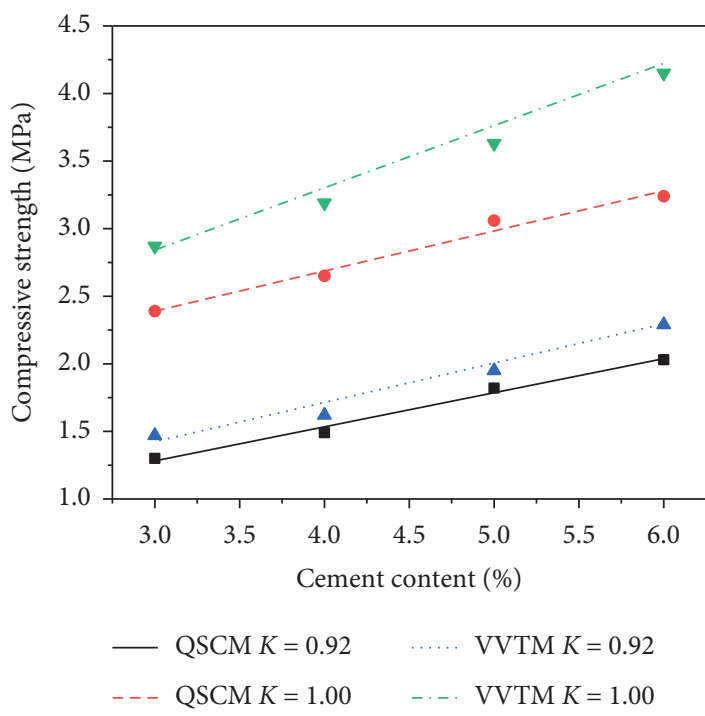

(c)
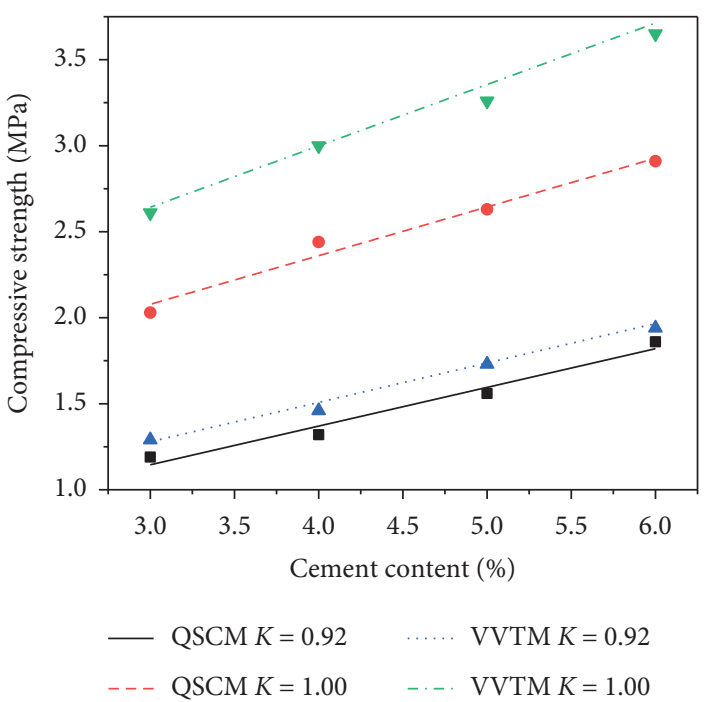

(b)

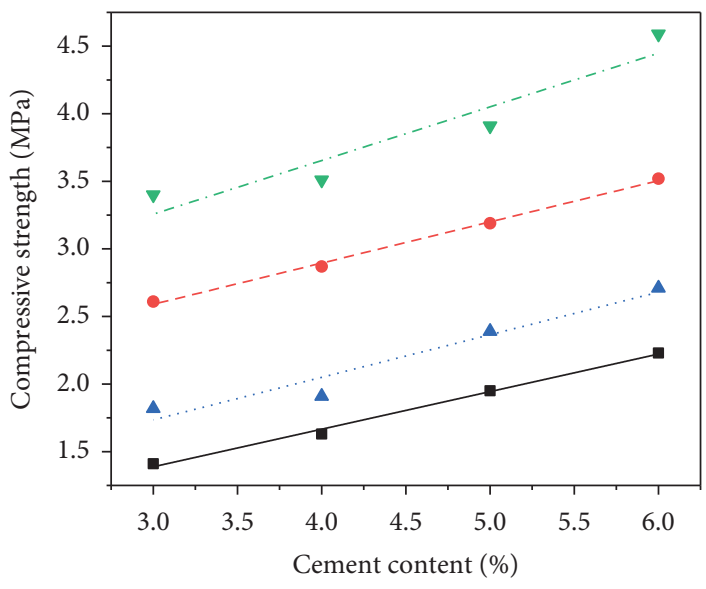

- $\operatorname{QSCM} K=0.92$
- - $\operatorname{QSCM}$

(d)

FIGURE 4: Influence of cement content on UCS of CSL compacted using VVCM and QSCM. (a) 7 d. (b) 14 d. (c) $28 \mathrm{~d}$. (d) $90 \mathrm{~d}$.

The cylindrical specimens with dimensions $100 \mathrm{~mm}(\Phi) \times$ $100 \mathrm{~mm}(h)$ were compacted using vertical vibration testing equipment (VVTE) manufactured based on simulating the principle and working condition of directional vibratory roller. The VVTE for VVCM is schematically given in Figure 1, and the working parameters of VVTE are listed in Table 3 .

As displayed in Figure 1, VVTE is comprised of three parts: control platform, rotating device, and vibration system [36]. The control platform is used to adjust the working frequency of the rotating device, control the vibration time, and lift the vibration system. The rotating device is mainly composed of motor and transfer case. Vibration system is the most important part of VVTE, which is mainly composed of frame, vibration exciter, upper system, lower system, and vibrating hammer. The vibration exciter is designed according to the vibration device of vibratory roller. Similar to the vibrator of vibratory roller, the core structure of VVTE is vibration exciter, which includes two parallel vibration shafts and a group of eccentric blocks symmetrically installed on the two vibration shafts. In order to adjust the eccentricity, the eccentric block on each shaft is divided into a fixed eccentric block and a movable eccentric block. When the motor works, the single shaft rotation of the motor drives the rotation of two shafts with the same speed and in the opposite direction through the transfer box and drives the two groups of eccentric blocks of the vibrator to rotate at the same speed and in the opposite direction, so that the eccentric block produces centrifugal force. Due to the reverse rotation of the two eccentric blocks, the horizontal components of centrifugal force counteract each other and the vertical components overlap with each other. As a result, there is only vertical vibration and no horizontal 

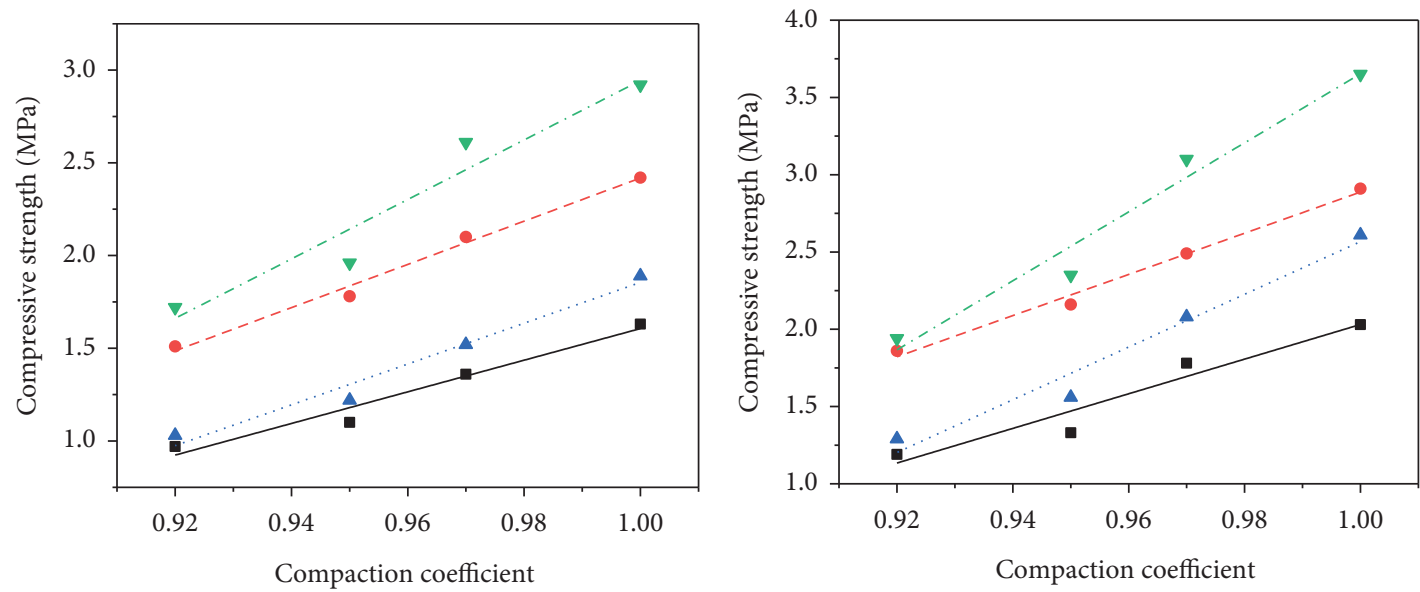

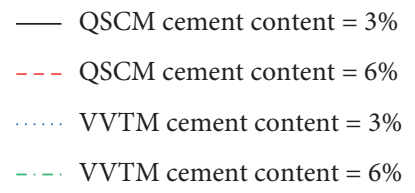

(a)

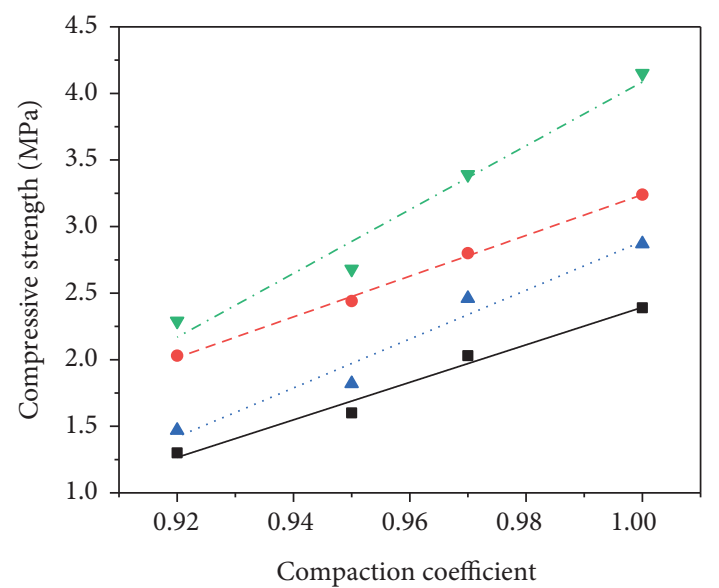

- QSCM cement content $=3 \%$
$---\quad$ QSCM cement content $=6 \%$
$\ldots . . \quad$ VVTM cement content $=3 \%$
.$--\quad$ VVTM cement content $=6 \%$

(c)

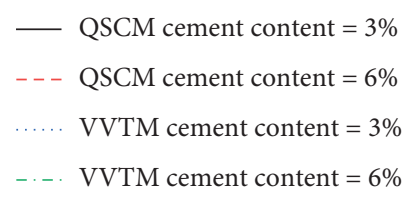

(b)

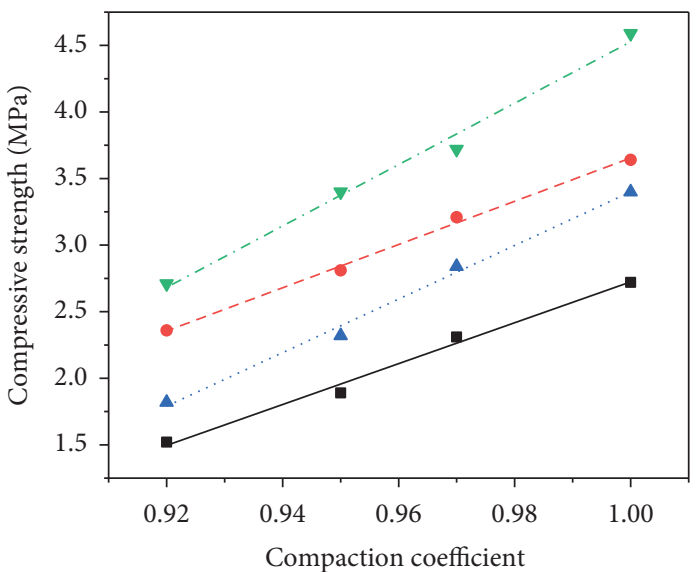

- QSCM cement content $=3 \%$

- - - QSCM cement content $=6 \%$

…. VVTM cement content $=3 \%$

VVTM cement content $=6 \%$

(d)

FIGURE 5: Influence of compaction coefficient on UCS of CSL compacted using VVCM and QSCM. (a) 7 d. (b) 14 d. (c) 28 d. (d) 90 d.

vibration, which ensures the stability of VVTE equipment and the compaction effect of vertical vibration.

(1) Determining Maximum Dry Density and Optimum Water Content. During the process of specimen preparation, the loess was smashed over $5 \mathrm{~mm}$ round screen after drying in an oven at a temperature lower than $50^{\circ} \mathrm{C}$ for approximately 6-8 hours until its mass stabilized; the water was then sprayed, evenly mixed, and put into a container with a cover sealed for 8 hours. Afterward, cement was added successively and mixed again. The mixtures were then poured five times into a mold with an inner diameter of $102 \mathrm{~mm}$ and a height of $116 \mathrm{~mm}$ and then were compacted and vibrated with VVTE for $140 \mathrm{~s}$. Finally, the specimens were removed and their mass and heights were measured; moreover, the dry density was calculated. In the same manner, five specimens with different water contents (about 2\% in turn near the optimum water content) were fabricated, and their dry density was calculated. Different dry density-water content curves were obtained, and the optimum water content $\left(\omega_{\text {opt }}\right)$ and maximum dry density $\left(\rho_{\max }\right)$ were determined from the curve vertex.

(2) Specimen Preparation. In this study, four groups of cement content $(3 \%, 4 \%, 5 \%$, and $6 \%)$ and compaction 


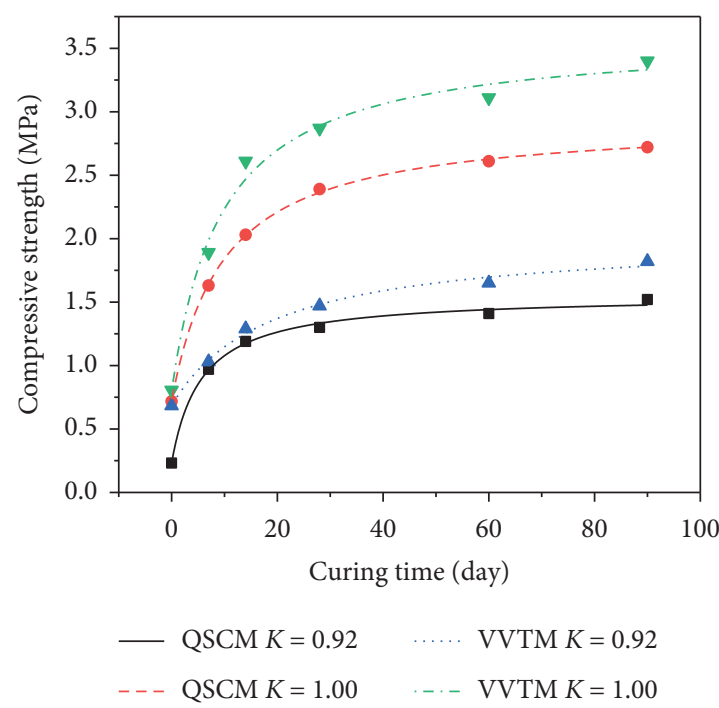

(a)

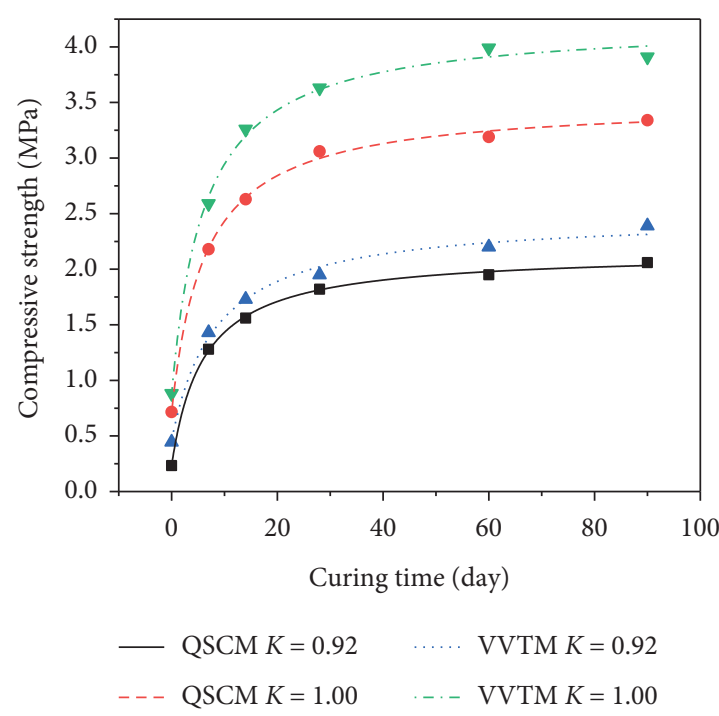

(c)

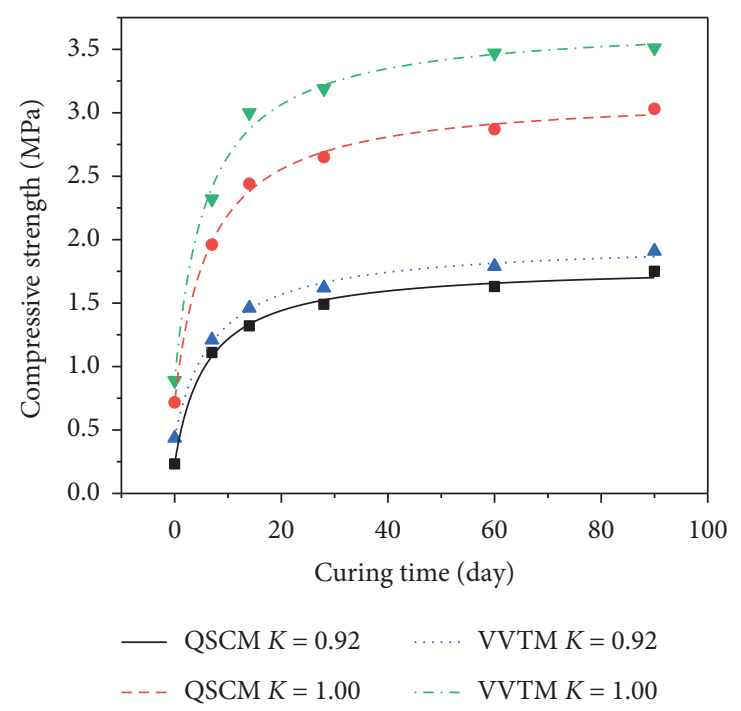

(b)

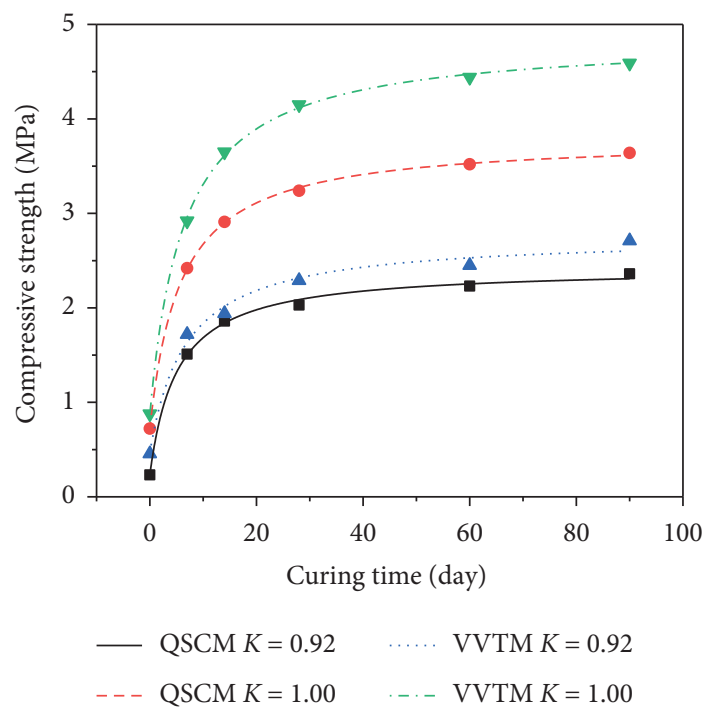

(d)

Figure 6: Influence of curing time on UCS of CSL compacted using VVCM and QSCM. (a) Cement content $=3 \%$. (b) Cement content $=4 \%$. (c) Cement content $=5 \%$. (d) Cement content $=6 \%$.

coefficient $(0.92,0.95,0.97$, and 1.00$)$ were conducted for the cylindrical specimen $(\Phi 100 \mathrm{~mm} \times h 100 \mathrm{~mm})$. On the basis of $\rho_{\text {max }}, \omega_{\text {opt }}$, and compaction coefficient, the mass of CSL specimen was calculated using the following equation:

$$
m=K \times \rho_{\max } \times V \times\left(1+\omega_{\text {opt }}\right),
$$

where $m$ is the mass of CSL specimen (g); $K$ is the compaction coefficient; $\rho_{\max }$ is the maximum dry density $(\mathrm{g} /$ $\left.\mathrm{cm}^{3}\right) ; V$ is the volume of CSL specimen $\left(\mathrm{cm}^{3}\right) ; \omega_{\text {opt }}$ is the optimum water content (\%).

The mixtures were vibrated and compacted with VVTE, and the vibration compaction time of CSL specimens was determined by controlling the height of specimens. Afterward, the specimens were demolded and wrapped in plastic sheets and stored in a curing room (the air temperature was
$20 \pm 2^{\circ} \mathrm{C}$ and the humidity was $95 \%$ ) for $7,14,28,60$, and 90 days. Finally, six replicate specimens were prepared.

2.2.2. QSCM. According to the heavy compaction test (HCTZ1) in the Code for Soil Test of Railway Engineering (TB101022010) [37], the compaction test was carried out to determine the maximum dry density and optimum water content of CSL. In a similar way, QSCM was adopted to fabricate specimens $(\Phi$ $100 \mathrm{~mm} \times h 100 \mathrm{~mm}$ ). The standard technical parameters of heavy compaction test (HCT-Z1) are shown in Table 4.

\subsubsection{Laboratory Evaluation of Mechanical Properties}

(1) Unconfined Compressive Strength. After curing for 7, 14, 28,60 , and 90 days, the prepared specimens were immersed 
TABLE 8: SPS of CSL compacted using VVCM and QSCM.

\begin{tabular}{|c|c|c|c|c|c|c|}
\hline \multirow{2}{*}{ Compaction method } & \multirow{2}{*}{ Curing time (days) } & \multirow{2}{*}{ Cement content $(\%)$} & \multicolumn{4}{|c|}{ SPS at different compaction coefficients ( $\mathrm{MPa})$} \\
\hline & & & 0.92 & 0.95 & 0.97 & 1.00 \\
\hline \multirow{20}{*}{ QSCM } & \multirow{4}{*}{7} & 3 & 0.09 & 0.15 & 0.17 & 0.27 \\
\hline & & 4 & 0.16 & 0.23 & 0.30 & 0.36 \\
\hline & & 5 & 0.19 & 0.27 & 0.33 & 0.44 \\
\hline & & 6 & 0.25 & 0.31 & 0.40 & 0.52 \\
\hline & \multirow{4}{*}{14} & 3 & 0.16 & 0.21 & 0.27 & 0.32 \\
\hline & & 4 & 0.23 & 0.29 & 0.37 & 0.43 \\
\hline & & 5 & 0.27 & 0.35 & 0.44 & 0.53 \\
\hline & & 6 & 0.32 & 0.40 & 0.51 & 0.62 \\
\hline & \multirow{4}{*}{28} & 3 & 0.24 & 0.29 & 0.35 & 0.40 \\
\hline & & 4 & 0.29 & 0.36 & 0.44 & 0.52 \\
\hline & & 5 & 0.34 & 0.42 & 0.52 & 0.63 \\
\hline & & 6 & 0.37 & 0.45 & 0.58 & 0.72 \\
\hline & \multirow{4}{*}{60} & 3 & 0.26 & 0.33 & 0.40 & 0.44 \\
\hline & & 4 & 0.32 & 0.40 & 0.48 & 0.57 \\
\hline & & 5 & 0.37 & 0.46 & 0.58 & 0.69 \\
\hline & & 6 & 0.40 & 0.49 & 0.63 & 0.79 \\
\hline & \multirow{4}{*}{90} & 3 & 0.28 & 0.36 & 0.42 & 0.46 \\
\hline & & 4 & 0.34 & 0.41 & 0.50 & 0.61 \\
\hline & & 5 & 0.39 & 0.49 & 0.60 & 0.72 \\
\hline & & 6 & 0.41 & 0.52 & 0.66 & 0.82 \\
\hline \multirow{20}{*}{ VVCM } & \multirow{4}{*}{7} & 3 & 0.12 & 0.21 & 0.27 & 0.45 \\
\hline & & 4 & 0.22 & 0.33 & 0.45 & 0.58 \\
\hline & & 5 & 0.26 & 0.38 & 0.52 & 0.71 \\
\hline & & 6 & 0.33 & 0.45 & 0.63 & 0.83 \\
\hline & \multirow{4}{*}{14} & 3 & 0.22 & 0.3 & 0.42 & 0.52 \\
\hline & & 4 & 0.3 & 0.41 & 0.58 & 0.72 \\
\hline & & 5 & 0.37 & 0.5 & 0.70 & 0.88 \\
\hline & & 6 & 0.44 & 0.6 & 0.82 & 1.04 \\
\hline & \multirow{4}{*}{28} & 3 & 0.32 & 0.43 & 0.56 & 0.68 \\
\hline & & 4 & 0.39 & 0.53 & 0.66 & 0.87 \\
\hline & & 5 & 0.46 & 0.61 & 0.80 & 1.05 \\
\hline & & 6 & 0.49 & 0.64 & 0.91 & 1.18 \\
\hline & \multirow{4}{*}{60} & 3 & 0.35 & 0.47 & 0.62 & 0.70 \\
\hline & & 4 & 0.43 & 0.55 & 0.74 & 0.92 \\
\hline & & 5 & 0.48 & 0.61 & 0.88 & 1.12 \\
\hline & & 6 & 0.52 & 0.69 & 1.00 & 1.31 \\
\hline & \multirow{4}{*}{90} & 3 & 0.36 & 0.54 & 0.63 & 0.74 \\
\hline & & 4 & 0.48 & 0.59 & 0.79 & 0.99 \\
\hline & & 5 & 0.53 & 0.67 & 0.93 & 1.18 \\
\hline & & 6 & 0.57 & 0.74 & 1.05 & 1.34 \\
\hline
\end{tabular}

in water with a temperature of $20 \pm 2^{\circ} \mathrm{C}$ for 24 hours. The unconfined compressive strength (UCS) was conducted in accordance with the Code for Soil Test of Railway Engineering (TB10102-2010) [37]. In this test, a WAW-100 universal material testing machine was adopted in a strain-control mode with an axial strain rate of $1 \mathrm{~mm} / \mathrm{min}$ (see Figure 2).

(2) Splitting Strength. Previous studies have indicated that the splitting strength of CSL is considerably lower than UCS, thus leading to poor crack resistance and then causing water infiltration, subgrade collapse, and other diseases [38]. Therefore, the splitting strength of CSL was investigated to ensure the stability and durability of CSL subgrade.

Since there are no requirements and test methods of splitting strength for CSL in TB10102-2010, T0806-1994 of the Test Methods of Materials Stabilized with Inorganic
Binders for Highway Engineering (JTG E51-2009) was carried out to test the splitting strength of CSL [39]. The CSL specimens were cured for $7,14,28,60$, and 90 days and immersed in water with a temperature of $20 \pm 2^{\circ} \mathrm{C}$ for 24 hours. The splitting strength test was then conducted using a strain-control mode and the axial strain rate was $1 \mathrm{~mm} / \mathrm{min}$. The splitting strength was calculated using the following equation:

$$
R_{i}=0.0125256 \times \frac{P}{h},
$$

where $R_{i}$ is the splitting strength (MPa); $P$ is the maximum loading pressure leading to specimen failure $(\mathrm{N}) ; h$ is the height of specimen after immersion ( $\mathrm{mm})$.

(3) Resilient Modulus. According to the strength meter method of the Code for Soil Test of Railway Engineering 
TABLE 9: SPS ratio of CSL compacted using VVCM to CSL compacted using QSCM.

\begin{tabular}{|c|c|c|c|c|c|}
\hline \multirow[t]{2}{*}{ Curing time (days) } & \multirow[t]{2}{*}{ Cement content (\%) } & \multicolumn{4}{|c|}{$\begin{array}{c}\text { SPS ratio of CSL compacted using VVCM to CSL compacted } \\
\text { using QSCM }\end{array}$} \\
\hline & & 0.92 & 0.95 & 0.97 & 1.00 \\
\hline \multirow{4}{*}{7} & 3 & 1.33 & 1.40 & 1.59 & 1.67 \\
\hline & 4 & 1.38 & 1.43 & 1.50 & 1.61 \\
\hline & 5 & 1.37 & 1.41 & 1.58 & 1.61 \\
\hline & 6 & 1.32 & 1.45 & 1.58 & 1.60 \\
\hline \multirow{4}{*}{14} & 3 & 1.38 & 1.43 & 1.56 & 1.63 \\
\hline & 4 & 1.30 & 1.41 & 1.57 & 1.67 \\
\hline & 5 & 1.37 & 1.43 & 1.59 & 1.66 \\
\hline & 6 & 1.38 & 1.50 & 1.61 & 1.68 \\
\hline \multirow{4}{*}{28} & 3 & 1.33 & 1.48 & 1.60 & 1.70 \\
\hline & 4 & 1.34 & 1.47 & 1.50 & 1.67 \\
\hline & 5 & 1.35 & 1.45 & 1.54 & 1.67 \\
\hline & 6 & 1.32 & 1.42 & 1.57 & 1.64 \\
\hline \multirow{4}{*}{60} & 3 & 1.35 & 1.42 & 1.55 & 1.59 \\
\hline & 4 & 1.34 & 1.38 & 1.54 & 1.61 \\
\hline & 5 & 1.30 & 1.35 & 1.52 & 1.62 \\
\hline & 6 & 1.30 & 1.41 & 1.59 & 1.66 \\
\hline \multirow{4}{*}{90} & 3 & 1.29 & 1.50 & 1.50 & 1.61 \\
\hline & 4 & 1.41 & 1.44 & 1.58 & 1.62 \\
\hline & 5 & 1.36 & 1.37 & 1.53 & 1.63 \\
\hline & 6 & 1.39 & 1.42 & 1.59 & 1.63 \\
\hline
\end{tabular}

(TB10102-2010) [37], the resilient modulus of CSL was tested (see Figure 3 ). Then the resilient modulus was calculated using the following equation:

$$
E_{e}=\frac{\pi p d}{4 l} \times\left(1-\mu^{2}\right)
$$

where $E_{e}$ is the resilient modulus $(\mathrm{MPa}) ; p$ is the progressive load $(\mathrm{MPa}) ; d$ is the diameter of bearing plate $(\mathrm{mm}) ; l$ is the resilient deformation ( $\mathrm{mm}) ; \mu$ is Poisson's coefficient of finegrained soil; and the value is 0.25 .

\section{Testing Results and Discussion}

3.1. Comparison between VVCM and QSCM. Table 5 lists the results of maximum dry density and optimum water content of the CSL compacted using VVCM and QSCM under different cement content. As seen from Table 5, the optimum water content determined using VVCM is $3 \%-6 \%$ lower than that of QSCM, with an average of 5\%. And the maximum dry density is 1.012-1.016 times higher than that of QSCM, with a mean of 1.014 times. Compared with QSCM, VVCM can apply a vibratory force and generate resonance and relative motion to the CSL, so that the CSL can squeeze one another to form a framework. Consequently, the maximum dry density of the CSL is increased. In addition, a small amount of water is needed for lubrication, and the corresponding optimum water content is decreased [29].

\subsection{Mechanical Properties of the CSLs Compacted Using VVCM and QSCM}

3.2.1. Unconfined Compressive Strength. Table 6 shows the unconfined compressive strength (UCS) of the laboratory- produced CSL compacted using VVCM and QSCM, respectively. The cement contents of CSL are 3.0\%, 4.0\%, 5.0\%, and $6.0 \%$, and the curing time for CSL is $7,14,28,60$, and 90 days, respectively.

(1) Compaction Method. The UCS ratio of CSL compacted using VVCM to CSL compacted using QSCM is an index to compare the advantages of two compaction methods. Thus, Table 7 shows the UCS ratio of CSL compacted using VVCM to CSL compacted using QSCM (calculated according to Table 6). As indicated from Table 7, the average value of UCS compacted using VVCM is higher than that of QSCM with the same condition. The average UCS ratio of CSL compacted using VVCM to that using QSCM is 1.17. Moreover, the UCS of CSL compacted using VVCM can be increased by $17 \%$ compared with that by QSCM.

When the QSCM is used to prepare the specimen, the friction force between the particles prevents the particles from moving in a wide range. With the increase of static load, the friction force between particles increases accordingly, making it more difficult to move. Therefore, the QSCM can rarely achieve the ideal compaction result. For the specimen compacted using VVCM, the vibration of high frequency and strong pressure makes the compacted CSL produce vibration close to its own frequency. The friction between particles is eliminated by vibration. With the increase of vibration time, the interlocking between particles becomes more compact and the distribution is more uniform [32]. The UCS of CSL with different compaction methods just explains this point.

(2) Cement Content. Figure 4 shows the influence of cement content $(3 \%-6 \%)$ on the UCS of CSL at different curing time 

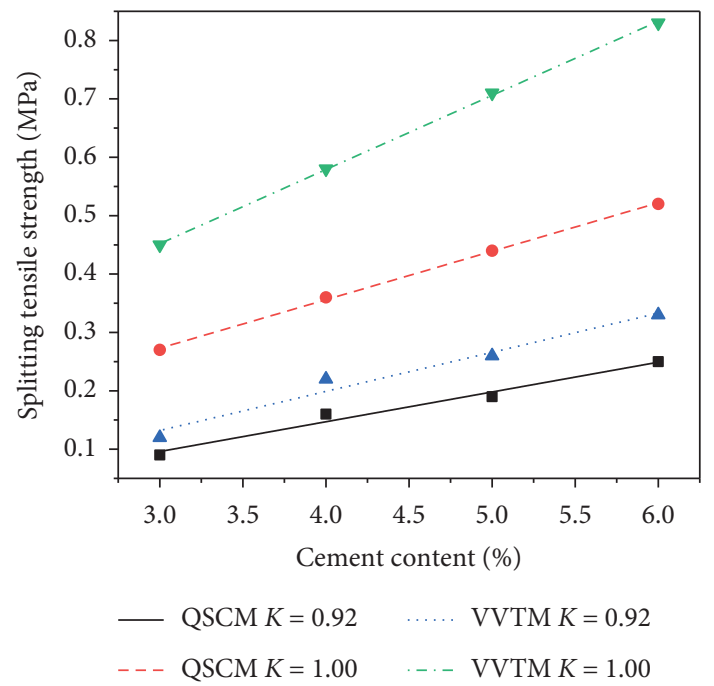

(a)

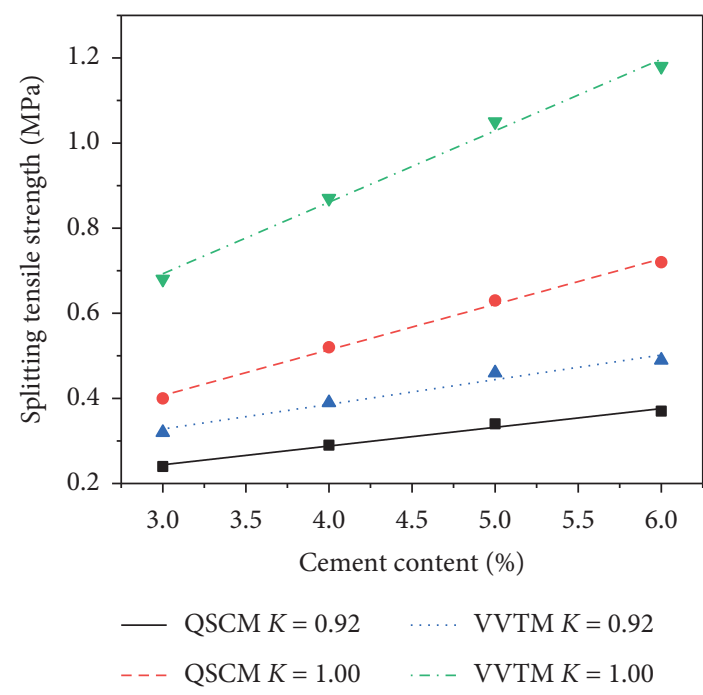

(c)

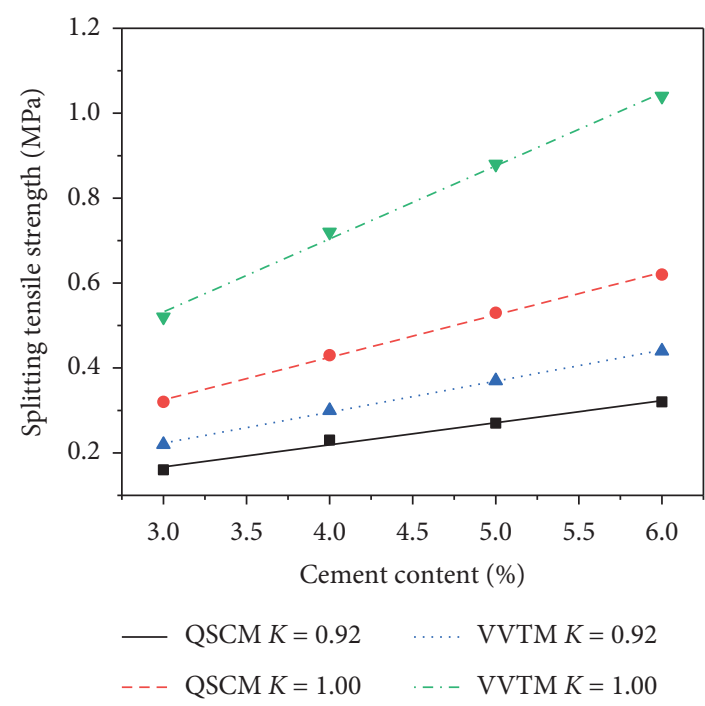

(b)

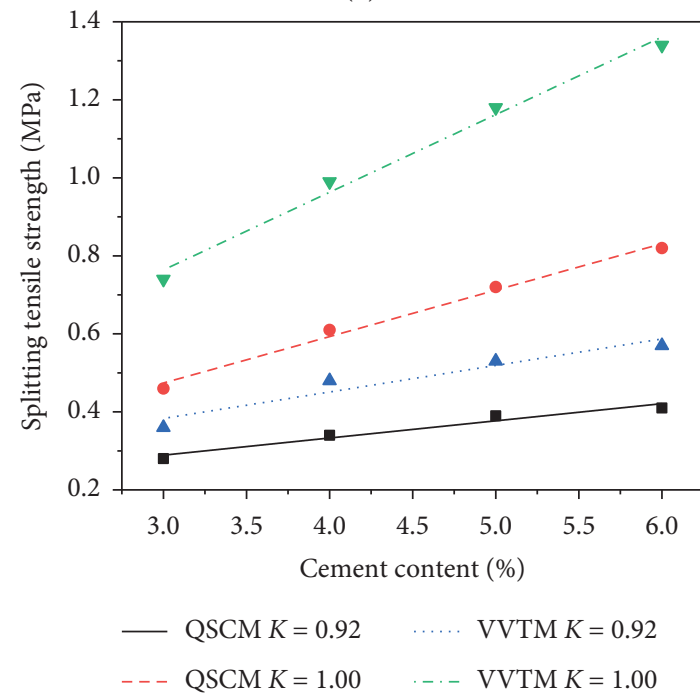

(d)

Figure 7: Influence of cement content on SPS of CSL compacted using VVCM and QSCM. (a) 7 d. (b) 14 d. (c) $28 \mathrm{~d}$. (d) $90 \mathrm{~d}$.

(7, 14, 28, and 90 days). As revealed from Figure 4, the UCS of CSL compacted using VVCM and QSCM increases approximately linearly with the increase of cement content at the same compaction coefficient. In particular, when the cement content increases by $1 \%$, the UCS of CSL compacted using VVCM and QSCM increases by $14.2 \%$ and $11.7 \%$ on average. The reason can be explained that the increase of cement content can lead to the increase of cement hydration crystal produced by cement hydration reaction, which directly enhances the adhesive force of mixture, thus improving the compressive strength of CSL.

(3) Compaction Coefficient. Figure 5 displays the influence of compaction coefficient $(0.92,0.95,0.97$, and 1.00) on the UCS of CSL at different curing time (7, 14, 28, and 90 days). According to Figure 5, the UCS of CSL compacted using VVCM and QSCM increases linearly with the increase of compaction coefficient; especially on the basis of Figure 5(c), when the compaction coefficient increases by $1 \%$, the average increases of UCS of CSL compacted using VVCM and QSCM are 9.0\% and 7.7\%, respectively. This is mainly due to the increase of compaction coefficient, the loess particles in the specimen are further arranged and compacted, the internal pores are decreased, and the contact areas of loess particles inside the specimen are increased. Therefore, the UCS of CSL increases as the compaction coefficient increases and the CSL specimen compacted using VVCM increases more significantly.

(4) Curing Time. Figure 6 shows the UCS growth curve of CSL with different cement content (3\%-6\%). As shown in Figure 6, the UCS growth curves of CSL in the two compaction methods (VVCM and QSCM) are similar. The UCS increases sharply at the initial stage, such as curing 

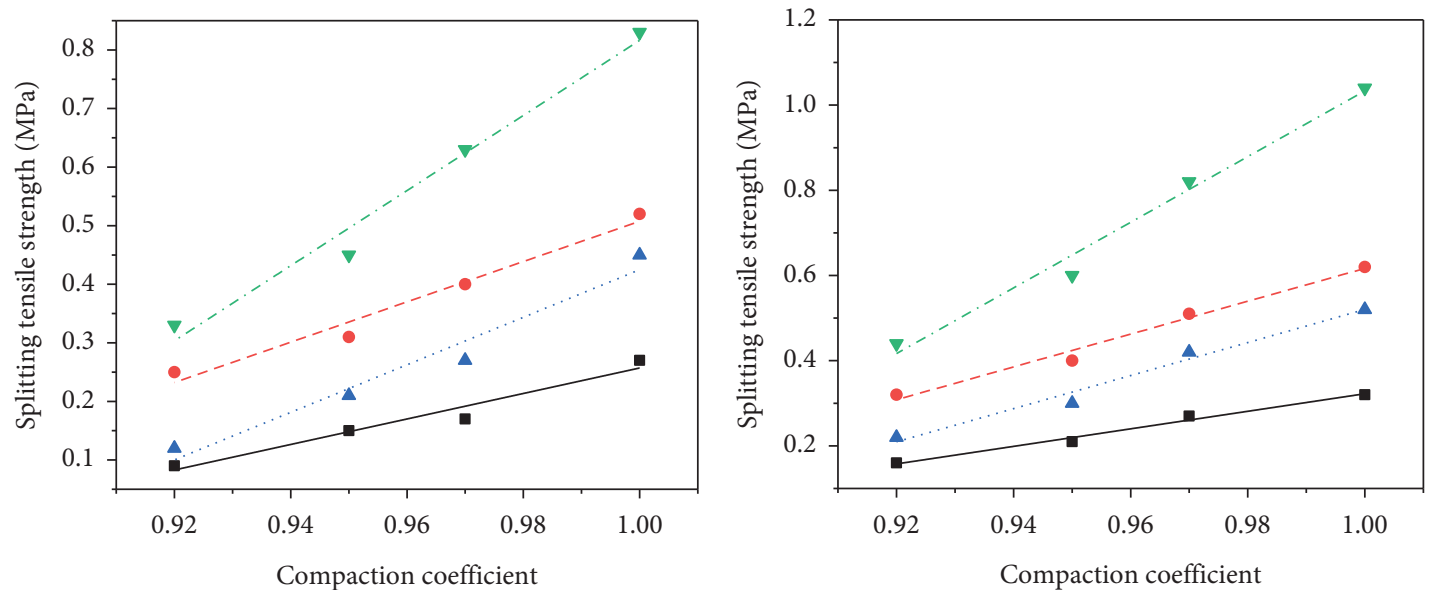

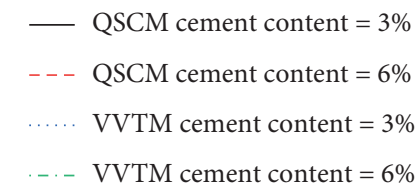

(a)

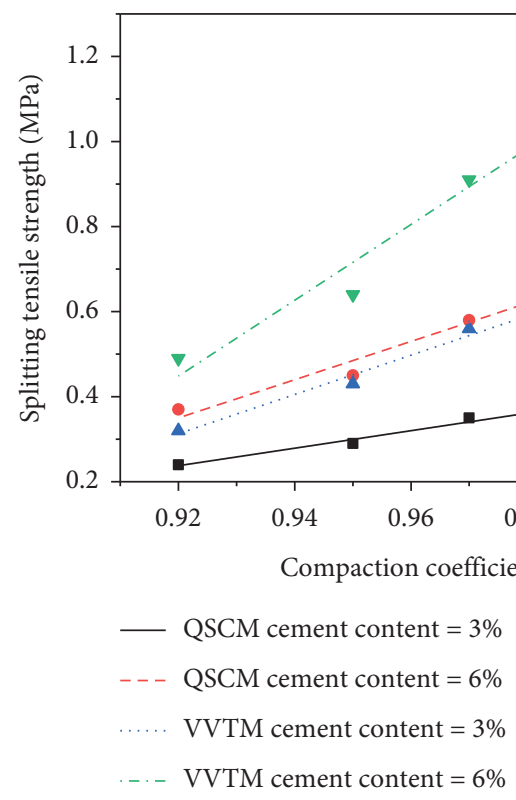

(c)

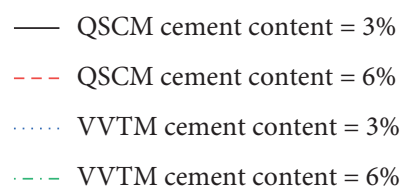

(b)

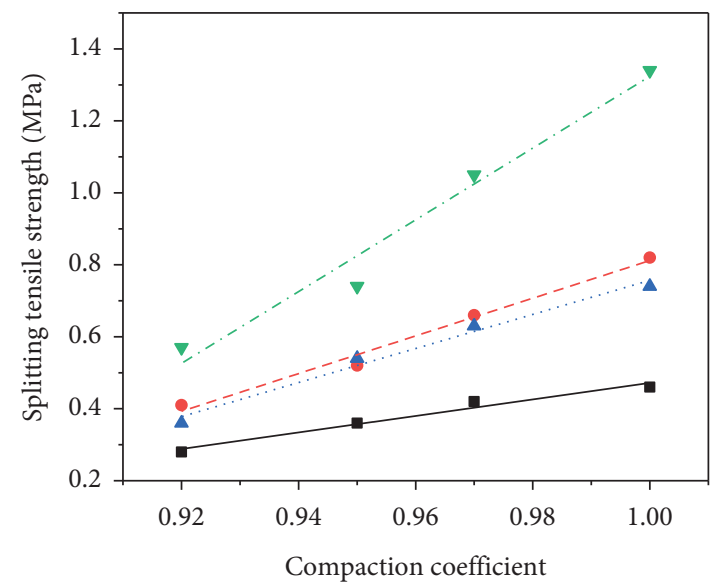

- QSCM cement content $=3 \%$
$-\ldots$ QSCM cement content $=6 \%$
$\ldots . . \quad$ VVTM cement content $=3 \%$
$\ldots$ VVTM cement content $=6 \%$

(d)

FIGURE 8: Influence of compaction coefficient on SPS of CSL compacted using VVCM and QSCM. (a) $7 \mathrm{~d}$. (b) $14 \mathrm{~d}$. (c) $28 \mathrm{~d}$. (d) $90 \mathrm{~d}$.

time of $0-14$ days, and after curing time of 28 days, it increases slowly. Afterward, the increasing tendency decreases and the UCS of CSL stabilizes after a curing time of 90 days. In accordance with the previous studies, Zhang et al. [14] and Su [15] indicated that the increase of CSL in strength primarily occurred in the first 14 days, and the growth rate is small in 28 to 90 days; finally, the intensity was steady in the stadium of 90 days. This phenomenon is closely correlated to the hydration mechanism of cement [40].

Under the same cement content, the average UCS of CSL prepared using QSCM for curing time of 7 days is
$72.2 \%$ of that for curing time of 28 days and $63.2 \%$ of the ultimate strength, and the average CSL prepared using VVCM for curing time of 7 days is $71.2 \%$ of that for curing time of 28 days and $61 \%$ of the average ultimate strength, which demonstrates that it is reliable to use $7 \mathrm{~d}$ UCS to control cement content in the design of CSL subgrade.

3.2.2. Splitting Strength. Table 8 provides the splitting strength (SPS) of the laboratory-produced CSL compacted using VVCM and QSCM, respectively. The cement contents 

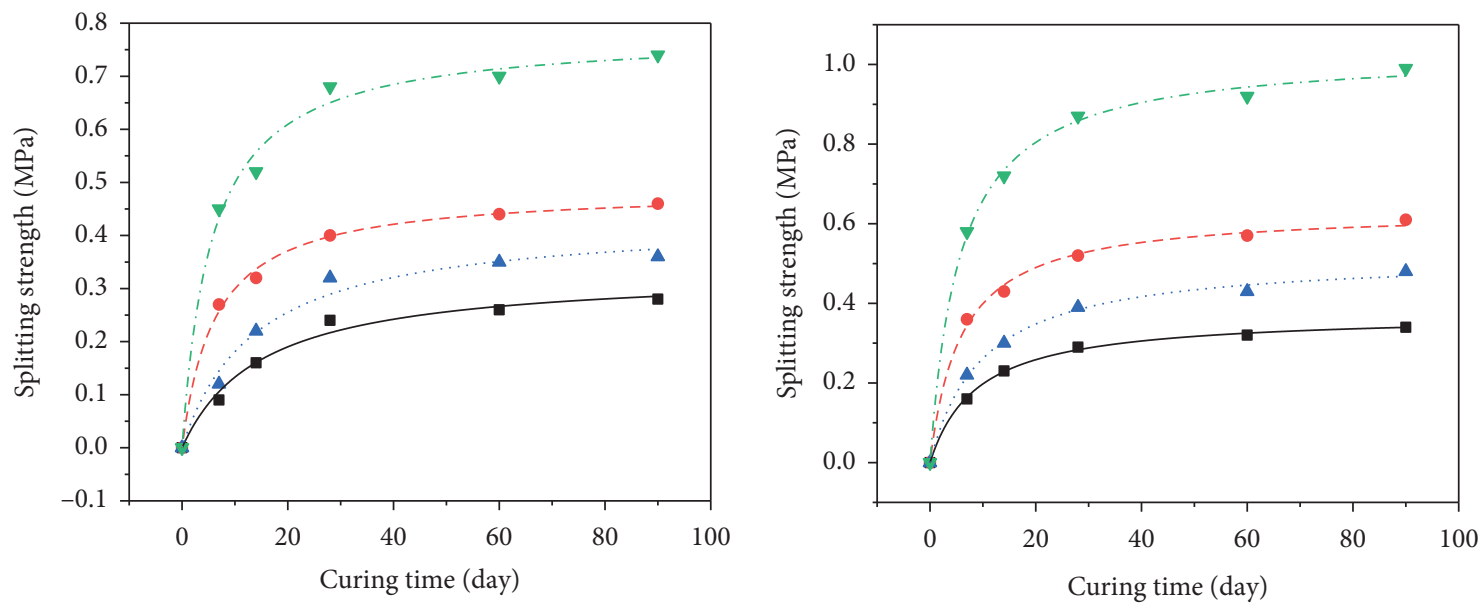

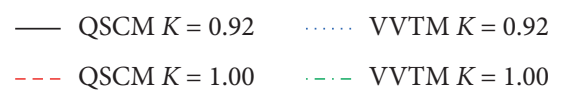

(a)

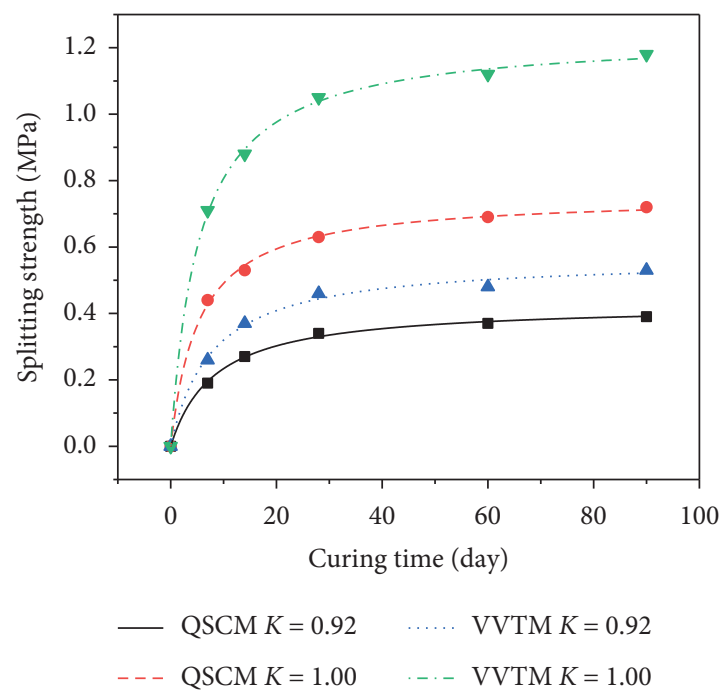

(c)

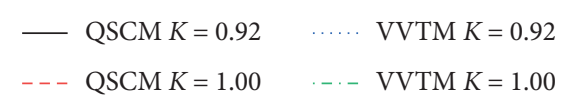

(b)

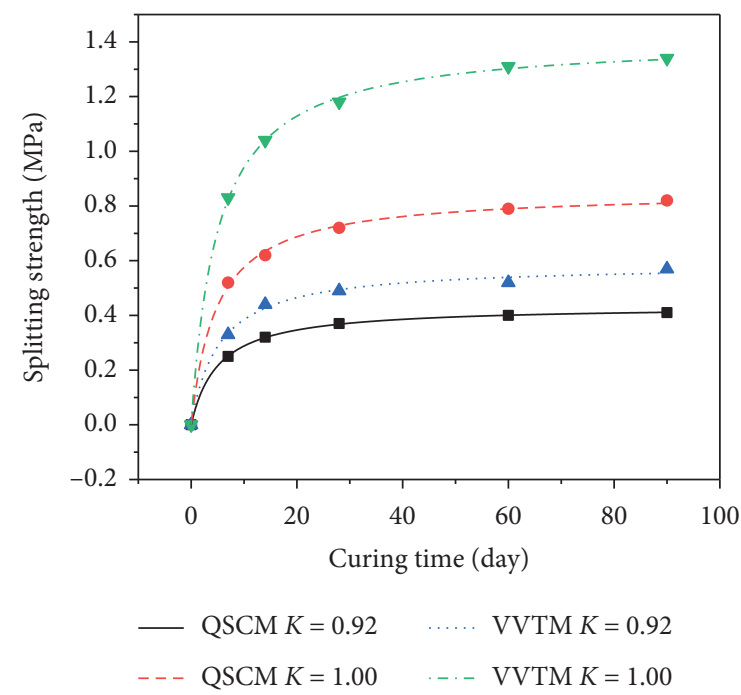

(d)

FIGURE 9: Influence of curing time on SPS of CSL compacted using VVCM and QSCM. (a) Cement content $=3 \%$. (b) Cement content $=4 \%$. (c) Cement content $=5 \%$. (d) Cement content $=6 \%$.

are $3.0 \%, 4.0 \%, 5.0 \%$, and $6.0 \%$, and the curing time is 7,14 , 28,60 , and 90 days, respectively.

(1) Compaction Method. Table 9 lists the SPS ratio of CSL compacted using VVCM to CSL compacted using QSCM (calculated according to Table 8). As calculated from Table 9, the average value of SPS compacted using VVCM is higher than that of QSCM, the same as the regularity of the UCS. The average SPS ratio of CSL compacted using VVCM to that using QSCM is 1.49. Moreover, the SPS of CSL compacted using VVCM can be increased by $49 \%$ compared with that using QSCM, and the increase of splitting strength is more significant than that of compressive strength at the same condition. Therefore, the compaction method has a greater influence on the SPS. This is consistent with Bahar's study which showed the dynamic compaction method was better than the static compaction method.

(2) Cement Content. Figure 7 shows the influence of cement content $(3 \%-6 \%)$ on the SPS of CSL at different curing time (7, 14, 28, and 90 days). As shown from Figure 7, the SPS growth trend of CSL compacted using VVCM and QSCM is the same as that of UCS, and the trend is approximately linear. Moreover, the SPS of CSL compacted using VVCM is higher than that using QSCM in the same condition. Particularly on the basis of Figure 7(c), when the cement content increases by $1 \%$, the SPS of CSL compacted using VVCM and QSCM is averagely increased by $17 \%$ and $18 \%$, respectively. Compared with the UCS of CSL, the effect of cement content on the SPS of CSL is significant. 
TABLE 10: Resilient modulus of CSL compacted using VVCM and QSCM.

\begin{tabular}{|c|c|c|c|c|c|c|}
\hline \multirow[t]{2}{*}{ Compaction method } & \multirow[t]{2}{*}{ Curing time (days) } & \multirow[t]{2}{*}{ Cement content (\%) } & \multicolumn{4}{|c|}{$\begin{array}{l}\text { RM of CSL compacted using VVCM and } \\
\text { QSCM (MPa) }\end{array}$} \\
\hline & & & 0.92 & 0.95 & 0.97 & 1.00 \\
\hline \multirow{20}{*}{ QSCM } & \multirow{4}{*}{7} & 3 & 252 & 293 & 343 & 386 \\
\hline & & 4 & 294 & 360 & 418 & 470 \\
\hline & & 5 & 348 & 416 & 468 & 523 \\
\hline & & 6 & 413 & 476 & 530 & 586 \\
\hline & \multirow{4}{*}{14} & 3 & 316 & 360 & 427 & 482 \\
\hline & & 4 & 368 & 449 & 522 & 599 \\
\hline & & 5 & 446 & 523 & 586 & 647 \\
\hline & & 6 & 521 & 589 & 661 & 749 \\
\hline & \multirow{4}{*}{28} & 3 & 354 & 420 & 478 & 532 \\
\hline & & 4 & 421 & 501 & 572 & 649 \\
\hline & & 5 & 502 & 573 & 641 & 705 \\
\hline & & 6 & 595 & 663 & 719 & 796 \\
\hline & \multirow{4}{*}{60} & 3 & 378 & 451 & 526 & 578 \\
\hline & & 4 & 456 & 542 & 623 & 706 \\
\hline & & 5 & 534 & 618 & 697 & 774 \\
\hline & & 6 & 627 & 696 & 771 & 856 \\
\hline & \multirow{4}{*}{90} & 3 & 406 & 479 & 553 & 624 \\
\hline & & 4 & 483 & 573 & 657 & 744 \\
\hline & & 5 & 569 & 646 & 731 & 807 \\
\hline & & 6 & 661 & 739 & 813 & 896 \\
\hline \multirow{20}{*}{ VVCM } & \multirow{4}{*}{7} & 3 & 280 & 337 & 398 & 479 \\
\hline & & 4 & 321 & 421 & 502 & 583 \\
\hline & & 5 & 369 & 466 & 571 & 664 \\
\hline & & 6 & 450 & 538 & 631 & 709 \\
\hline & \multirow{4}{*}{14} & 3 & 335 & 410 & 508 & 612 \\
\hline & & 4 & 412 & 521 & 616 & 737 \\
\hline & & 5 & 477 & 612 & 692 & 815 \\
\hline & & 6 & 552 & 660 & 793 & 951 \\
\hline & \multirow{4}{*}{28} & 3 & 382 & 466 & 555 & 654 \\
\hline & & 4 & 459 & 581 & 669 & 811 \\
\hline & & 5 & 537 & 670 & 782 & 860 \\
\hline & & 6 & 661 & 749 & 856 & 1011 \\
\hline & \multirow{4}{*}{60} & 3 & 423 & 514 & 642 & 717 \\
\hline & & 4 & 483 & 634 & 760 & 868 \\
\hline & & 5 & 582 & 723 & 816 & 952 \\
\hline & & 6 & 683 & 773 & 933 & 1061 \\
\hline & \multirow{4}{*}{90} & 3 & 447 & 560 & 664 & 780 \\
\hline & & 4 & 541 & 659 & 788 & 930 \\
\hline & & 5 & 632 & 749 & 892 & 985 \\
\hline & & 6 & 707 & 865 & 968 & 1120 \\
\hline
\end{tabular}

(3) Compaction Coefficient. Figure 8 displays the influence of compaction coefficient $(0.92,0.95,0.97$, and 1.00) on the SPS of CSL at different curing time $(7,14,28$, and 90 days). According to Figure 8, the SPS of CSL compacted using VVCM and QSCM increases linearly with the increase of compaction coefficient at certain cement content $(3 \%-6 \%)$, especially on the basis of Figure 8(c), when the compaction coefficient increases by $1 \%$, the average increase of SPS for CSL compacted using VVCM is 11\%, larger than that using QSCM 7.4\% (at the condition that the cement content is $3 \%$ and curing time is 28 days). Furthermore, the slope of the splitting strength of the specimen compacted using VVCM is larger than that using QSCM, thus showing the superiority of VVCM.

In addition, the $28 \mathrm{~d}$ SPS of CSL with a compaction coefficient of 0.97 and cement content of $3 \%$ is $0.35 \mathrm{MPa}$, which is equivalent to the $28 \mathrm{~d}$ SPS of CSL with a compaction coefficient of 0.92 and cement content of $6 \%$. Therefore, it can be known that the cement content can be appropriately reduced by increasing the compaction coefficient of CSL subgrade.

(4) Curing Time. Figure 9 displays the SPS growth curve of CSL with different cement content (3\%-6\%). As displayed in Figure 9, the SPS growth curve of CSL in the two compaction methods (VVCM and QSCM) is similar to the UCS growth trend. Under the same cement content, the SPS of CSL compacted using QSCM for curing time of 28 days is averagely $86.4 \%$ of the ultimate strength, and the SPS of CSL compacted using VVCM for curing time of 28 days is averagely $87.1 \%$ of the ultimate strength, which shows that the SPS of CSL for curing time of 28 days is quite accurate to predict the ultimate strength. 
TABLE 11: RM ratio of CSL compacted using VVCM to CSL compacted using QSCM.

\begin{tabular}{|c|c|c|c|c|c|}
\hline \multirow[t]{2}{*}{ Curing time (days) } & \multirow[t]{2}{*}{ Cement content (\%) } & \multicolumn{4}{|c|}{$\begin{array}{c}\text { RM ratio of CSL compacted using VVCM to CSL compacted } \\
\text { using QSCM }\end{array}$} \\
\hline & & 0.92 & 0.95 & 0.97 & 1.00 \\
\hline \multirow{4}{*}{7} & 3 & 1.11 & 1.15 & 1.16 & 1.24 \\
\hline & 4 & 1.09 & 1.17 & 1.20 & 1.24 \\
\hline & 5 & 1.06 & 1.12 & 1.22 & 1.27 \\
\hline & 6 & 1.09 & 1.13 & 1.19 & 1.21 \\
\hline \multirow{4}{*}{14} & 3 & 1.06 & 1.14 & 1.19 & 1.27 \\
\hline & 4 & 1.12 & 1.16 & 1.18 & 1.23 \\
\hline & 5 & 1.07 & 1.17 & 1.18 & 1.26 \\
\hline & 6 & 1.06 & 1.12 & 1.20 & 1.27 \\
\hline \multirow{4}{*}{28} & 3 & 1.08 & 1.11 & 1.16 & 1.23 \\
\hline & 4 & 1.09 & 1.16 & 1.17 & 1.25 \\
\hline & 5 & 1.07 & 1.17 & 1.22 & 1.22 \\
\hline & 6 & 1.11 & 1.13 & 1.19 & 1.27 \\
\hline \multirow{4}{*}{60} & 3 & 1.12 & 1.14 & 1.22 & 1.24 \\
\hline & 4 & 1.06 & 1.17 & 1.22 & 1.23 \\
\hline & 5 & 1.09 & 1.17 & 1.17 & 1.23 \\
\hline & 6 & 1.09 & 1.11 & 1.21 & 1.24 \\
\hline \multirow{4}{*}{90} & 3 & 1.10 & 1.17 & 1.20 & 1.25 \\
\hline & 4 & 1.12 & 1.15 & 1.20 & 1.25 \\
\hline & 5 & 1.11 & 1.16 & 1.22 & 1.22 \\
\hline & 6 & 1.07 & 1.17 & 1.19 & 1.25 \\
\hline
\end{tabular}

3.2.3. Resilient Modulus. Table 10 illustrates the resilient modulus (RM) of the laboratory-produced CSL compacted using VVCM and QSCM, respectively.

(1) Compaction Method. Table 11 shows the RM ratio of CSL compacted using VVCM to that using QSCM (calculated according to Table 10). As calculated from Table 11, the average value of RM compacted using VVCM is higher than that of QSCM, the same regularity as the UCS and SPS. The average RM ratio of CSL compacted using VVCM and QSCM is 1.17.

The microstructure of the specimen analyzed by SEM [9] shows that there are large pores in the CSL specimen compacted using QSCM, which reduces the contact area between loess particles and then shows low strength and weak resistance to deformation, while the VVCM can significantly change the internal structure of filler, which is conducive to the mutual filling of loess particles and makes the distribution of loess particles more uniform. As a result, the internal pores of the CSL specimens become smaller, and the overall structure is denser, which improves the intercalation and friction between loess particles and then shows higher strength and stronger resistance to deformation.

(2) Cement Content. Figure 10 shows the influence of cement content $(3 \%-6 \%)$ on the RM of CSL at different curing time (7, 14, 28, and 90 days). As illustrated from Figure 10, the RM of CSL compacted using VVCM and QSCM increases approximately linearly as the cement content increases. Particularly on the basis of Figure $10(\mathrm{c})$, when the cement content increases by $1 \%$, the RM of CSL compacted using VVCM and QSCM, respectively, increases by $17.2 \%$ and $16.1 \%$ on average.
(3) Compaction Coefficient. Figure 11 shows the influence of compaction coefficient $(0.92,0.95,0.97$, and 1.00$)$ on the RM of CSL at different curing time (7, 14, 28, and 90 days). With reference to Figure 11, the RM of CSL compacted using VVCM and QSCM increases approximately linearly with the increase of compaction coefficient at a certain cement content (3\%-6\%). According to Figure 11(c), when the compaction coefficient increases by $1 \%$, the average increase of RM for CSL compacted using VVCM and QSCM is 7\% and 5\%, respectively. The increase in the compaction coefficient improves the strength of the specimen, and the rebound deformation of the specimen decreases accordingly, which reflects the trend that the RM increases with the increase in the compaction coefficient.

(4) Curing Time. According to Table 10, the RM growth curves of CSL with different cement content (3\%-6\%) and different curing time $(0,7,14,28,60$, and 90 days) are illustrated in Figure 12. As displayed in Figure 12, the RM growth curves of CSL in the two compaction methods (VVCM and QSCM) are similar to the UCS and SPS growth trend. Under the same cement content, the RM prepared using QSCM for curing time of 28 days is $86.6 \%-89.3 \%$ of the ultimate strength, with an average of $86.6 \%$. And the CSL prepared using VVCM for curing time of 28 days is $84.1 \%-89.7 \%$ of the ultimate strength, with an average of $86.9 \%$.

3.3. Correlation of Mechanical Properties between LaboratoryProduced Specimens and Field Core Samples. A comparison of mechanical properties among the laboratory-produced 


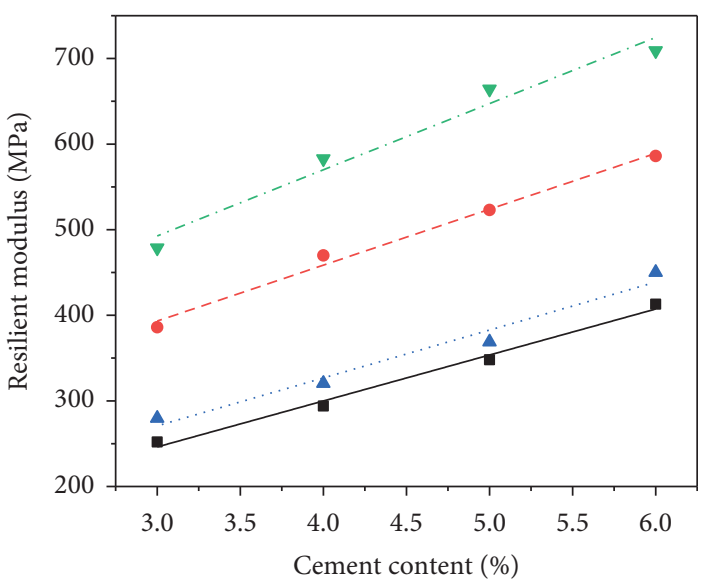

$\begin{array}{ll}\text { - QSCM } K=0.92 & \cdots \cdot \operatorname{VVTM} K=0.92 \\ --\operatorname{QSCM} K=1.00 & \text { VVTM } K=1.00\end{array}$

(a)

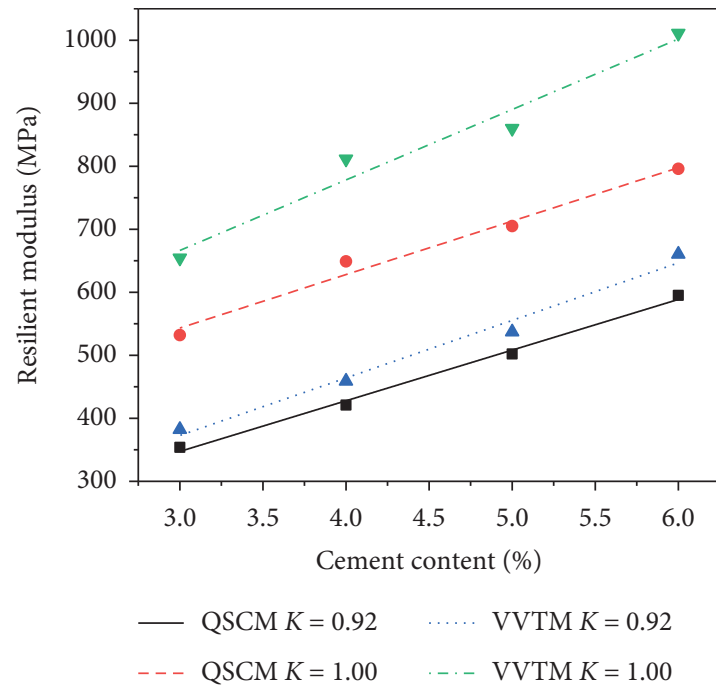

(c)

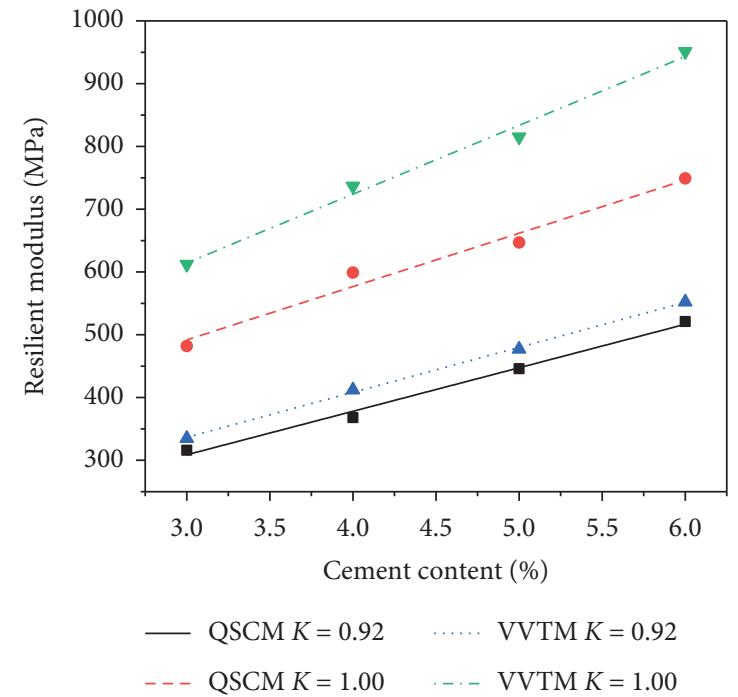

(b)

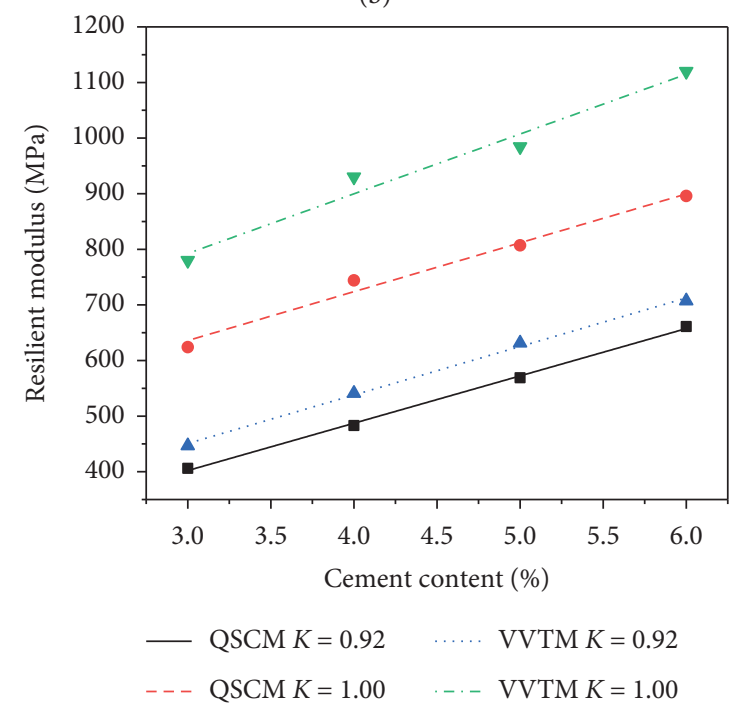

(d)

Figure 10: Influence of cement content on RM of CSL compacted using VVCM and QSCM. (a) 7 d. (b) 14 d. (c) 28 d. (d) 90 d.

CSL using VVCM, QSCM, and the field core samples (FCSs) was carried out to investigate and select a suitable compaction method for the practical CSL assessment. The field CSL subgrade was compacted using a $22 \mathrm{~T}$ vibratory roller for 8-10 times until reaching a compaction coefficient over 0.95. To maintain the same curing environment, the CSL specimens were firstly compacted using VVCM and QSCM in a laboratory with the same dry density as the field and then were transferred to the same field environmental condition as the FCSs. The Xi'an-Hancheng intercity railway for the field measurement was located in Hancheng City, Shaanxi province in China. The cement content used was $6 \%$ and the curing time was 7 days.

The comparison of UCS and RM among the laboratoryproduced CSL using VVCM, QSCM, and the FCSs with compaction coefficient of 0.95 and 0.96 is listed in Tables 12 and 13 , where $q_{\mathrm{cV}}$ is the UCS of the specimens formed using
VVCM, $q_{\mathrm{cQ}}$ is the UCS of the specimens formed using QSCM, $q_{\mathrm{cF}}$ is the UCS of the FCSs, $E_{\mathrm{cV}}$ is the RM of the specimens formed using $\mathrm{VVCM}, E_{\mathrm{cQ}}$ is the RM of the specimens formed using QSCM, and $E_{\mathrm{CF}}$ is the RM of the FCSs.

As displayed from Tables 12 and 13, the correlation between the UCS of CSL specimens prepared using VVCM and the FCSs is as high as $83.4 \%$ on average, while that of CSL specimen prepared using QSCM is less than 64\%. And the RM of CSL compacted using VVCM and QSCM is averagely $89.4 \%$ and $73.9 \%$ compared to the FCSs. This shows that the strength of CSL specimen compacted using VVCM is closer to that of FCSs. Therefore, the mechanical strength of field CSL construction can be simulated and predicted more accurately using VVCM than QSCM.

The mechanical strength of CSL compacted using VVCM higher than that using QSCM may be attributed that the loess is in a relatively flowing state under VVCM, which 

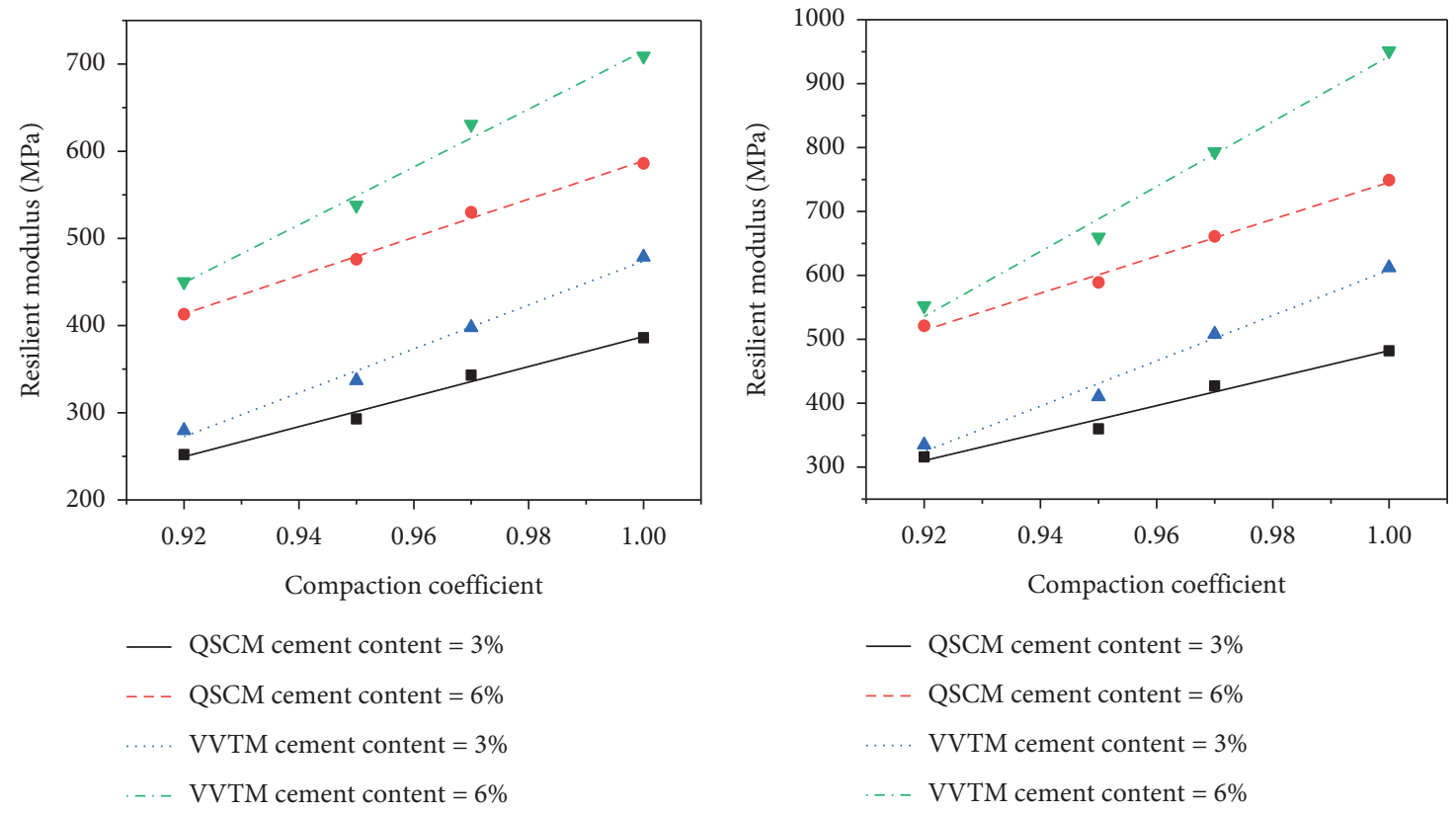

(a)

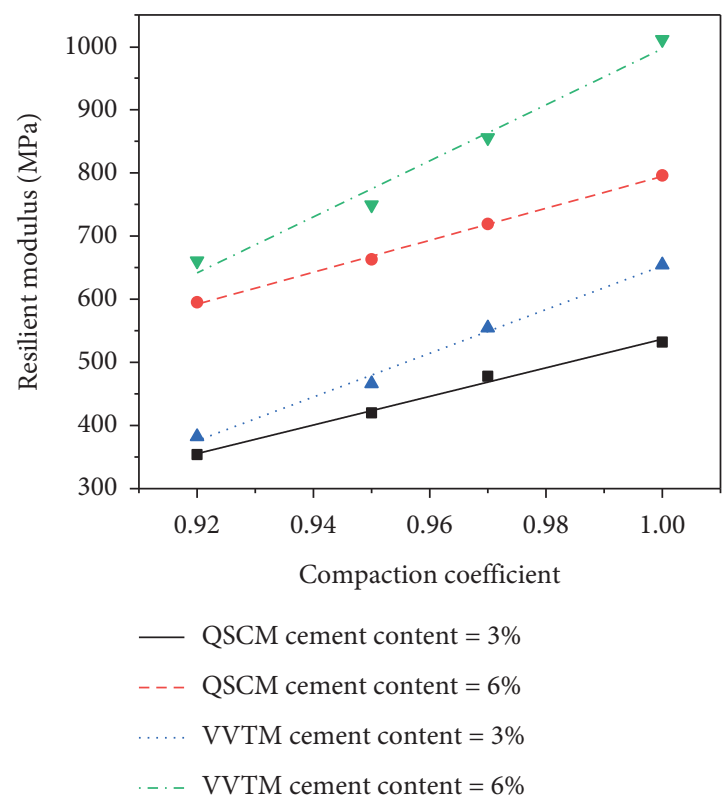

(c)

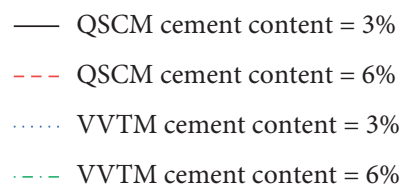

(b)

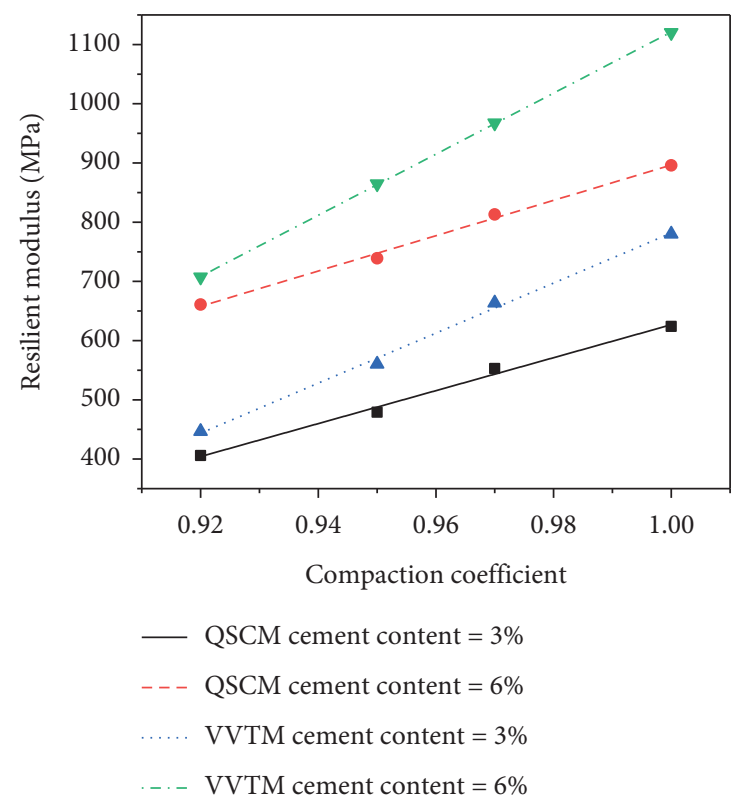

(d)

FIGURE 11: Influence of compaction coefficient on RM of CSL compacted using VVCM and QSCM. (a) $7 \mathrm{~d}$. (b) $14 \mathrm{~d}$. (c) $28 \mathrm{~d}$. (d) $90 \mathrm{~d}$.

effectively reduces the resistance between particles. To some extent, it is conducive to the formation of a dense state between particles of different sizes, so that the pores are smaller. While the QSCM simply relies on the vertical pressure and constantly overcomes the shear force between particles. The particles are further broken and compacted, and the particles are relatively static, which can rarely make the particles fill each other, thus forming larger pores, 


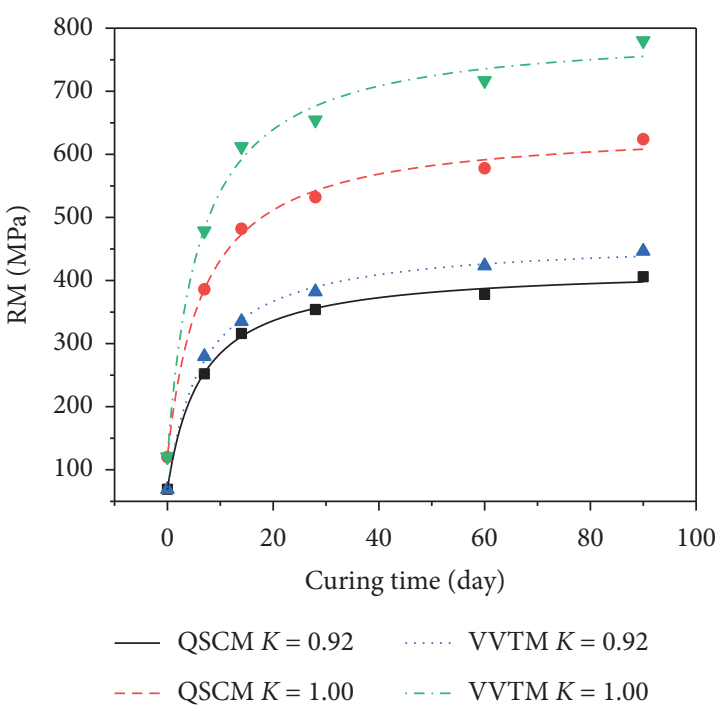

(a)

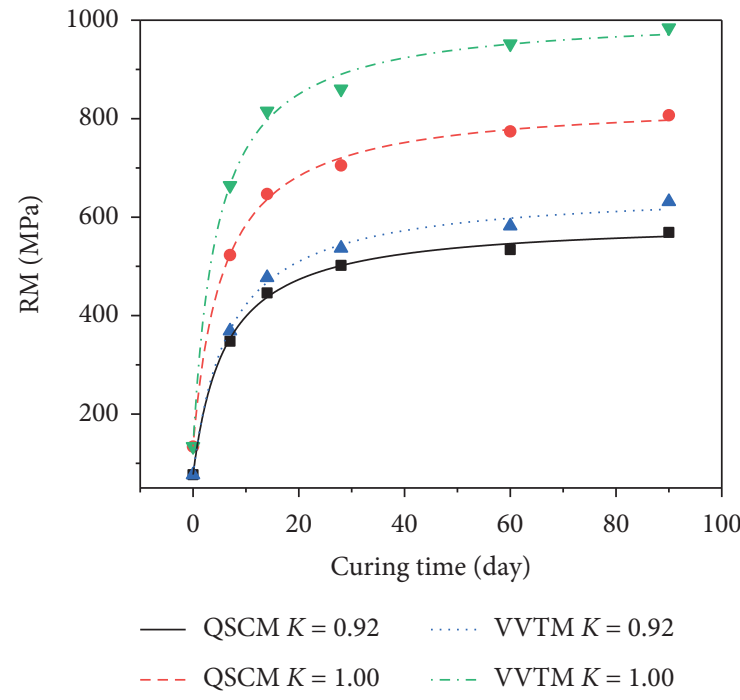

(c)

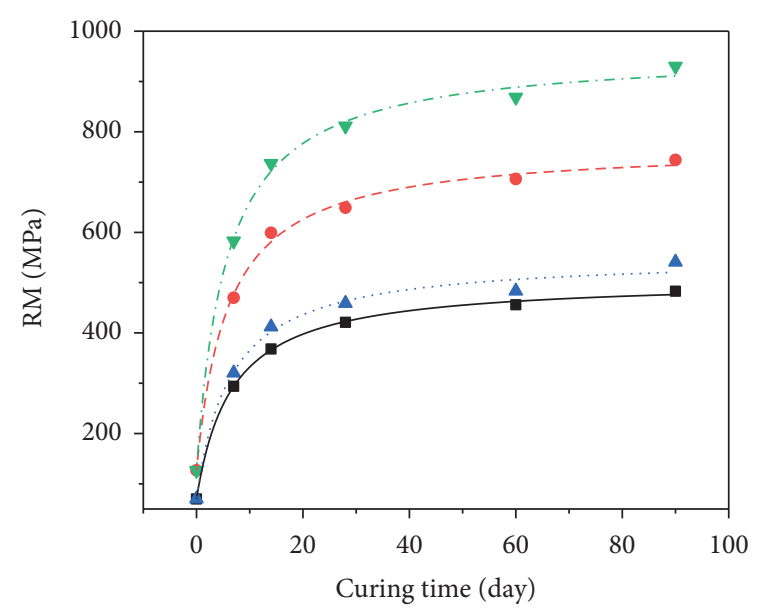

$-\operatorname{QSCM} K=0.92$
$-\cdots$

(b)

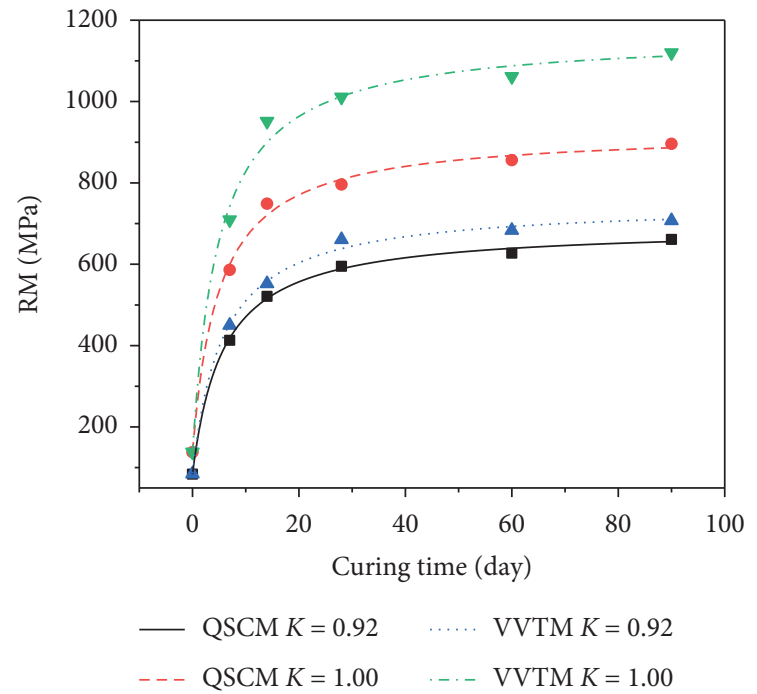

(d)

FIGURE 12: Influence of curing time on RM of CSL compacted using VVCM and QSCM. (a) Cement content $=3 \%$. (b) Cement content $=4 \%$. (c) Cement content $=5 \%$. (d) Cement content $=6 \%$.

TABLE 12: Comparison of UCS among specimens compacted using VVCM, QSCM, and FCSs.

\begin{tabular}{lccccc}
\hline Compaction coefficient & $q_{\mathrm{cF}}(\mathrm{MPa})$ & $q_{\mathrm{cV}}(\mathrm{MPa})$ & $q_{\mathrm{cQ}}(\mathrm{MPa})$ & $q_{\mathrm{cV}} / q_{\mathrm{cF}}(\%)$ & 83.8 \\
\hline 0.95 & 2.16 & 1.81 & 1.38 & $q_{\mathrm{cQ}} / q_{\mathrm{cF}}(\%)$ \\
0.96 & 2.64 & 2.19 & 1.63 & 83.0 & 61.7 \\
\hline
\end{tabular}

TABLE 13: Comparison of RM among specimens compacted using VVCM, QSCM, and FCSs.

\begin{tabular}{lccccc}
\hline Compaction coefficient & $E_{\mathrm{cF}}(\mathrm{MPa})$ & $E_{\mathrm{cV}}(\mathrm{MPa})$ & $E_{\mathrm{cQ}}(\mathrm{MPa})$ & $E_{\mathrm{cV}} / R_{\mathrm{cF}}(\%)$ & 89.4 \\
\hline 0.95 & 170 & 152 & 128 & $E_{\mathrm{cQ}} / E_{\mathrm{cF}}(\%)$ \\
0.96 & 196 & 175 & 142 & 89.3 & 75.3 \\
\hline
\end{tabular}


making the contact area smaller, and showing a smaller mechanical strength.

Moreover, the strength of the FCSs higher than laboratory-produced specimens may be explained by the influence of the mold size. Due to the influence of the mold size, the particles can rarely be fully moved and arranged in the process of compaction, thus affecting the internal structure $[9,29,32,41]$. However, the loess particles can be arranged sufficiently during the field vibration rolling, so as to improve the strength of the subgrade. Similar results can be obtained from the cement-stabilized gravels [42, 43].

\section{Conclusions}

The compaction method including VVCM and QSCM was investigated to compare the mechanical properties of CSL specimens, and the influencing factors were analyzed. Moreover, field measurements were also carried out. The following conclusions are drawn from the results:

(1) The maximum dry density and optimum water content of laboratory-compacted CSL using VVCM were 1.012-1.016 times and 0.94-0.97 times that of QSCM.

(2) The CSL specimen produced using VVCM has a higher unconfined compressive strength, splitting strength, and resilient modulus than that of CSL produced using QSCM.

(3) The unconfined compressive strength, splitting strength, and resilient modulus of the specimen produced using the two methods VVCM and QSCM increase linearly as the cement content and compaction coefficient increase, while the mechanical strength growth curve experiences three periods of increasing sharply, increasing slowly, and stabilizing with the curing time increased.

(4) The compressive strength of CSL produced using VVCM has a higher correlation with the field core samples than that using QSCM; the VVCM can be conducted to approximately evaluate the mechanical properties of field CSL construction. Therefore, VVCM can provide a reference for CSL design.

The mechanical properties of the cement-stabilized loess compacted using vertical vibration compaction method for railway engineering were studied. Furthermore, the micromechanism of the vertical vibration compaction method superior to the traditional compaction method will be further conducted.

\section{Data Availability}

The data used to support the findings of this study are included within the article.

\section{Conflicts of Interest}

The authors declare that there are no conflicts of interest regarding the publication of this paper.

\section{Acknowledgments}

This research was supported by the Science and Technology Project of Shaanxi Provincial Department of Transportation (nos. 18-02K and 19-27K) and the Scientific Research of Central Colleges of China for Chang'an University (no. 300102218212). The authors gratefully acknowledge the financial support.

\section{References}

[1] S. S. Savvateev, N. I. Kriger, S. A. Lavrusevich et al., "Subsidences and erosion in loess soils," GeoJournal, vol. 15, no. 2, pp. 173-1767, 1987.

[2] Y. Wang and P. P. Yang, "Study on physical and mechanical characteristics of Q2 loess and micro-structure properties in Li-Shan," Advanced Materials Research, vol. 1065-1069, pp. 1846-1849, 2014.

[3] National Railway Administration, Code for Design of Intercity Railway (TB 10623-2014), China Railway Press, Beijing, China, 2014.

[4] National Railway Administration, Code for Design of Railway Earth Structure (TB10001-2016), China Railway Press, Beijing, China, 2016.

[5] W. Zhang, A. Guo, C. Lin et al., "Effects of cyclic freeze and thaw on engineering properties of compacted loess and limestabilized loess," Journal of Materials in Civil Engineering, vol. 31, no. 9, Article ID 04019205, 2019.

[6] D. Evstatiev, "Loess improvement methods," Engineering Geology, vol. 25, no. 2-4, pp. 341-366, 1988.

[7] Y. Gao, H. Qian, X. Li et al., "Effects of lime treatment on the hydraulic conductivity and microstructure of Loess," Environmental Earth Sciences, vol. 77, no. 14, p. 529, 2018.

[8] H. M. Liu, L. M. Wang, P. Gao et al., "The mechanical properties of cement reinforced loess and pore microstructure characteristics," Applied Mechanics and Materials, vol. 527, pp. 25-30, 2014.

[9] K. Gu and B. Chen, "Loess stabilization using cement, waste phosphogypsum, fly ash and quicklime for self-compacting rammed earth construction," Construction and Building Materials, vol. 231, Article ID 117195, 2020.

[10] Y. Zhang, A. E. Johnson, and D. J. White, "Freeze-thaw performance of cement and fly ash stabilized loess," Transportation Geotechnics, vol. 21, Article ID 100279, 2019.

[11] F. Zhang, X. Pei, and X. Yan, "Physicochemical and mechanical properties of lime-treated loess," Geotechnical and Geological Engineering, vol. 36, no. 1, pp. 685-696, 2018.

[12] M. Zhao, W. Guo, L.-y. Chen, and S.-y. Wang, "Experiment on the frost resistance of modified phospho gypsum: a case used to improve Baozhong railway subgrade loess," Journal of Mountain Science, vol. 16, no. 12, pp. 2920-2930, 2019.

[13] B.-h. Yang, X.-z. Weng, J.-z. Liu et al., "Strength characteristics of modified polypropylene fiber and cement-reinforced loess," Journal of Central South University, vol. 24, no. 3, pp. 560-568, 2017.

[14] C.-1. Zhang, G.-1. Jiang, L.-j. Su, and G.-d. Zhou, "Effect of cement on the stabilization of loess," Journal of Mountain Science, vol. 14, no. 11, pp. 2325-2336, 2017.

[15] X. P. Su, "Research on the properties of collapsible loess reinforced by cement," Advanced Materials Research, vol. 1015, pp. 110-113, 2014.

[16] M. Ghadakpour, A. J. Choobbasti, S. S. Kutanaei et al., "Experimental study of impact of cement treatment on the 
shear behavior of loess and clay," Arabian Journal of Geosciences, vol. 13, no. 4, p. 184, 2020.

[17] M. Zamani and K. Badv, "Assessment of the geotechnical behavior of collapsible soils: a case study of the MohammadAbad railway station soil in Semnan," Geotechnical and Geological Engineering, vol. 37, no. 4, pp. 2847-2860, 2019.

[18] J. D. Wang, S. J. Peng, W. L. Xie et al., "Study on the cementimproved loess under the vibratory load by dynamic tests," Advanced Materials Research, vol. 838-841, pp. 1302-1308, 2013.

[19] S. Cui, W. Xie, J. Wang, and S. Huang, "Engineering properties of collapsible loess stabilized by cement Kiln dust," Soil Mechanics and Foundation Engineering, vol. 56, no. 5, pp. 328-335, 2019.

[20] X. Zhang, Y. Lu, X. Li et al., "Microscopic structure changes of Malan Loess after humidification in south Jingyang plateau, China," Environmental Earth Sciences, vol. 78, no. 10, p. 287, 2019.

[21] J. B. Croft, "The influence of soil mineralogical composition on cement stabilization," Géotechnique, vol. 17, no. 2, pp. 119-135, 1967.

[22] A. M. O. Mohamed, "The role of clay minerals in marly soils on its stability," Engineering Geology, vol. 57, no. 3-4, pp. 193-203, 2000.

[23] K. Uddin, A. S. Balasubramaniam, and D. T. Bergado, "Engineering behaviour of cement-treated Bangkok soft clay," Geotechniacal Enginering Journal, vol. 28, no. 1, pp. 89-119, 1997.

[24] F.-H. Lee, Y. Lee, S.-H. Chew, and K.-Y. Yong, "Strength and modulus of marine clay-cement mixes," Journal of Geotechnical and Geoenvironmental Engineering, vol. 131, no. 2, pp. 178-186, 2005.

[25] N. C. Consoli, D. Foppa, L. Festugato, and K. S. Heineck, "Key parameters for strength control of artificially cemented soils," Journal of Geotechnical and Geoenvironmental Engineering, vol. 133, no. 2, pp. 197-205, 2007.

[26] R. Bahar, M. Benazzoug, and S. Kenai, "Performance of compacted cement-stabilized soil," Cement and Concrete Comnosites, vol. 26, no. 7, pp. 812-820, 2004.

[27] R. Н. Денисов, Architectural Properties of Loess and Loessial Loam, Geological Press, 1956.

[28] G. R. Gao, "A structure theory for collapsing deformation of Loess soils," Chinese Journal of Geotechnical Engineering, vol. 4, pp. 1-10, 1990, in Chinese.

[29] Y. J. Jiang and L. F. Fan, "An investigation of mechanical behavior of cement-stabilized crushed rock material using different compaction methods," Construction and Building Materials, vol. 48, pp. 508-515, 2013.

[30] C. Deng, Y. Jiang, H. Lin, and X. Ji, "Mechanical-strengthgrowth law and predictive model for cement-stabilized macadam," Construction and Building Materials, vol. 215, pp. 582-594, 2019.

[31] Y. Hou, X. Ji, and X. Su, "Mechanical properties and strength criteria of cement-stabilised recycled concrete aggregate," International Journal of Pavement Engineering, vol. 20, no. 3, pp. 339-348, 2019.

[32] Y. Jiang and J. Xue, "Investigation into physical and mechanical properties of SRX-stabilised crushed rock using different compaction methods," International Journal of Pavement Engineering, vol. 20, no. 7, pp. 866-873, 2019.

[33] Y. J. Jiang, C. Q. Deng, Q. Li et al., "Effect of compaction methods on physical and mechanical properties of asphalt mixture," Journal of Materials in Civil Engineering, vol. 31, no. 6, Article ID 04019075, 2019.
[34] X. Ji, Y. Jiang, and Y. Liu, "Evaluation of the mechanical behaviors of cement-stabilized cold recycled mixtures produced by vertical vibration compaction method," Materials and Structures, vol. 49, no. 6, pp. 2257-2270, 2016.

[35] X. Ji, Y. Hou, X. Li, and T. Wang, "Comparison on properties of cement-stabilised gravel prepared by different laboratory compaction methods," Road Materials and Pavement Design, vol. 20, no. 4, pp. 991-1003, 2019.

[36] Y. Jiang, C. Deng, J. Xue, H. Liu, and Z. Chen, "Investigation of the fatigue properties of asphalt mixture designed using vertical vibration method," Road Materials and Pavement Design, vol. 21, no. 5, pp. 1454-1469, 2020.

[37] MOT (Ministry of Transport of the People's Republic of China), Code for Soil Test of Railway Engineering (TB101022010), China Communications Press, Beijing, China, 2010.

[38] H. Ma and Q. Ma, "Experimental studies on the mechanical properties of Loess stabilized with sodium carboxymethyl cellulose," Advances in Materials Science and Engineering, vol. 2019, Article ID 9375685, 8 pages, 2019.

[39] MOT (Ministry of Transport of the People's Republic of China), Test Methods of Materials Stabilized with Inorganic Binders for Highway Engineering. JTG E51-2009, China Communications Press, Beijing, China, 2009.

[40] H. L. Huang, H. F. Zhang, F. Zhao, X. F. Li, and Y. F. Li, "Analysis of Portland cement hydration mechanism and its material applications in engineering," Advanced Materials Research, vol. 578, pp. 121-124, 2012.

[41] C. Q. Deng, Y. J. Jiang, T. Tian, and Z. Chen, "Resilient modulus and influencing factors of vertical vibration compacted cement-stabilized macadam," International Journal of Pavement Engineering, 2019.

[42] L. Wang, X. Xie, and H. Luan, "Influence of laboratory compaction methods on shear performance of graded crushed stone," Journal of Materials in Civil Engineering, vol. 23, no. 10, pp. 1483-1487, 2011.

[43] Y. J. Jiang, K. J. Yuan, C. Q. Deng, and T. Tian, "Fatigue performance of cement-stabilized crushed gravel produced using vertical vibration compaction method," Journal of Materials in Civil Engineering, vol. 32, no. 11, 2020. 